OPEN ACCESS

Edited by:

Chaker Tlili,

Chongqing Institute of Green and Intelligent Technology, Chinese Academy of Sciences (CAS), China

Reviewed by:

Ying-Wu Lin,

University of South China, China

Wei Song,

Jilin University, China

*Correspondence:

Long Wu

longquan.good@163.com

Guozhen Liu

liuguozhen@cuhk.edu.cn

Weimin Zhang

zhwm1979@163.com

Specialty section:

This article was submitted to

Biosensors and Biomolecular

Electronics,

a section of the journal

Frontiers in Bioengineering and

Biotechnology

Received: 20 June 2021

Accepted: 22 July 2021

Published: 24 August 2021

Citation:

Wu L, Zhou S, Wang G, Yun Y, Liu G and Zhang W (2021) Nanozyme Applications: A Glimpse of Insight in

Food Safety.

Front. Bioeng. Biotechnol. 9:727886.

doi: 10.3389/fbioe.2021.727886

\section{Nanozyme Applications: A Glimpse of Insight in Food Safety}

\author{
Long Wu ${ }^{1,2 *}$, Shuhong Zhou ${ }^{2}$, Gonglei Wang ${ }^{3}$, Yonghuan Yun ${ }^{1}$, Guozhen Liu $^{3 *}$ and \\ Weimin Zhang ${ }^{1 *}$
}

${ }^{1}$ College of Food Science and Engineering, Hainan University, Haikou, China, ${ }^{2}$ Key Laboratory of Fermentation Engineering (Ministry of Education), College of Bioengineering and Food, Hubei University of Technology, Wuhan, China, ${ }^{3}$ School of Life and Health Sciences, The Chinese University of Hong Kong, Shenzhen, China

Nanozymes own striking merits, including high enzyme-mimicking activity, good stability, and low cost. Due to the powerful and distinguished functions, nanozymes exhibit widespread applications in the field of biosensing and immunoassay, attracting researchers in various fields to design and engineer nanozymes. Recently, nanozymes have been innovatively used to bridge nanotechnology with analytical techniques to achieve the high sensitivity, specificity, and reproducibility. However, the applications of nanozymes in food applications are seldom reviewed. In this review, we summarize several typical nanozymes and provide a comprehensive description of the history, principles, designs, and applications of nanozyme-based analytical techniques in food contaminants detection. Based on engineering and modification of nanozymes, the food contaminants are classified and then discussed in detail via discriminating the roles of nanozymes in various analytical methods, including fluorescence, colorimetric and electrochemical assay, surface-enhanced Raman scattering, magnetic relaxing sensing, and electrochemiluminescence. Further, representative examples of nanozymes-based methods are highlighted for contaminants analysis and inhibition. Finally, the current challenges and prospects of nanozymes are discussed.

Keywords: Food safety, artificial enzyme, colorimetric assays, peroxidase activity, enzyme mimics

\section{INTRODUCTION}

Nanomaterials have received widespread attention in fields like chemistry, biology, environment, medicine and health, aerospace, resources and energy, and so on (Huang et al., 2019d; Wu et al., 2019a; Sun et al., 2018). Regarding their specific properties on mechanical, electrical, magnetic, optical, and catalytic activities, all kind of nanomaterials have been prepared and studied. Nanozyme, a kind of specific nanomaterials with enzyme-mimicking activity, is more and more favored by researchers. Nanozymes have shown a broad range of applications in vitro detection and living systems (Liang and Yan 2019). They hold a promise to serve as direct surrogates of natural enzymes in the analytical methods, especially the immunoassays (Wu et al., 2019b).

Compared with natural enzymes, nanozymes are easier to be modified and purified. Besides, the size, morphology (e.g., nanospheres, nanosheet, nanorods, nanowires, etc.), and surface groups can contribute to the enzyme-like activity of nanozymes (Wang et al., 2019; Gao et al., 2020). In this regard, nanozymes could thus be flexibly used as an effective medium in the construction of analytical methods. As a particular kind of nanomaterials, nanozymes are usually conjugated with antibody or DNA sequences to construct signal amplification strategy (Zhu et al., 2017; Tao et al., 


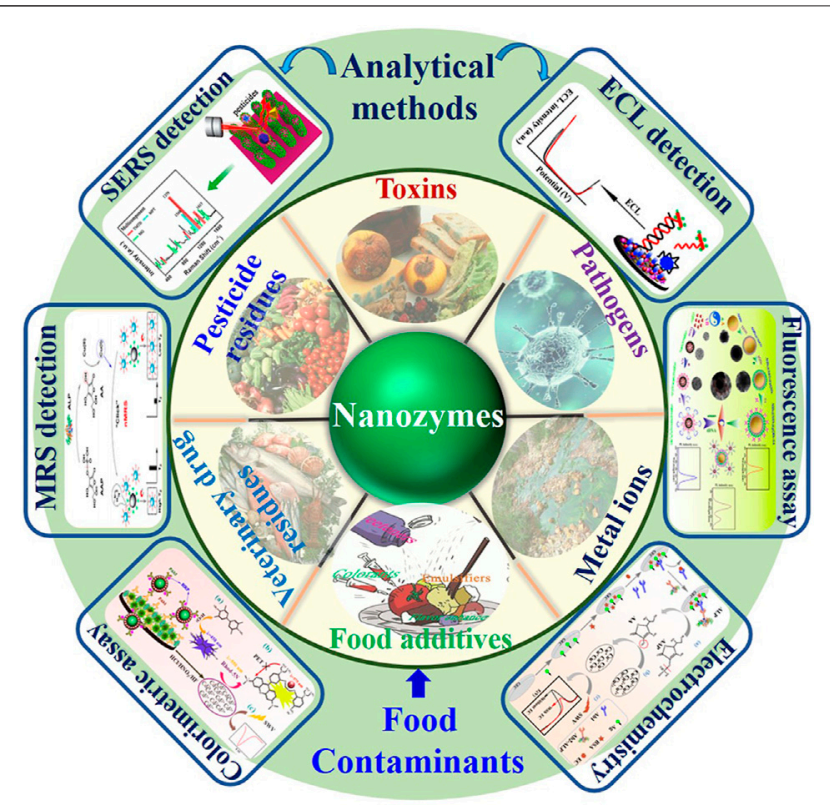

FIGURE 1 | The schematic presentation of nanozymes-based analytical techniques for the detection of different food contaminants (MRS, magnetic relaxing sensing; SERS, surface enhanced Raman scattering; ECL, electrochemiluminescence).

2020). When combined with traditional concepts of optical, electrochemical, or colorimetric assays, the analytical methods with lower detection limits can be developed.

On the other hand, food contaminants, a kind of toxic substances that is harmful to human, have increasingly grown in complexity and followed up on new public health issues, novel safety emergencies, and emerging consumer demands (Huang et al., 2019a). The complexity of the pollutants and food matrices brings great challenge to the analytical methods. For instance, Alternaria can generate several toxic secondary metabolites, like alternariol, alternariol monomethyl ether, altenuene, tentoxin, and tenuazonic acid, which are widely found in sorghum, sunflower seeds, cereals, tomatoes, wine, beers, apple juices, and beverages (Pinto and Patriarca 2017). Various analytical strategies have been developed to monitor their occurrence in foods or food production chain. Obviously, those wet-chemistrybased analytical methods have been gradually replaced by powerful techniques that enable high enhancements in accuracy, precision, and detection limits. The new technologies can get over difficulties of conventional methods, such as timeconsuming analysis, laborious procedures, and high cost.

The development of novel "rapid" detection methods has decreased detection time dramatically and thus could solve the main concerns of most of the analytical methods. Hence, a new frontier of nanozymes in food contaminants detection gives a glimpse of insight in this concept (Figure 1). In this review, an overview of emerging methods based on nanozymes is provided, with a focus on their varieties, surface modifications, and applications in food contaminants analysis.
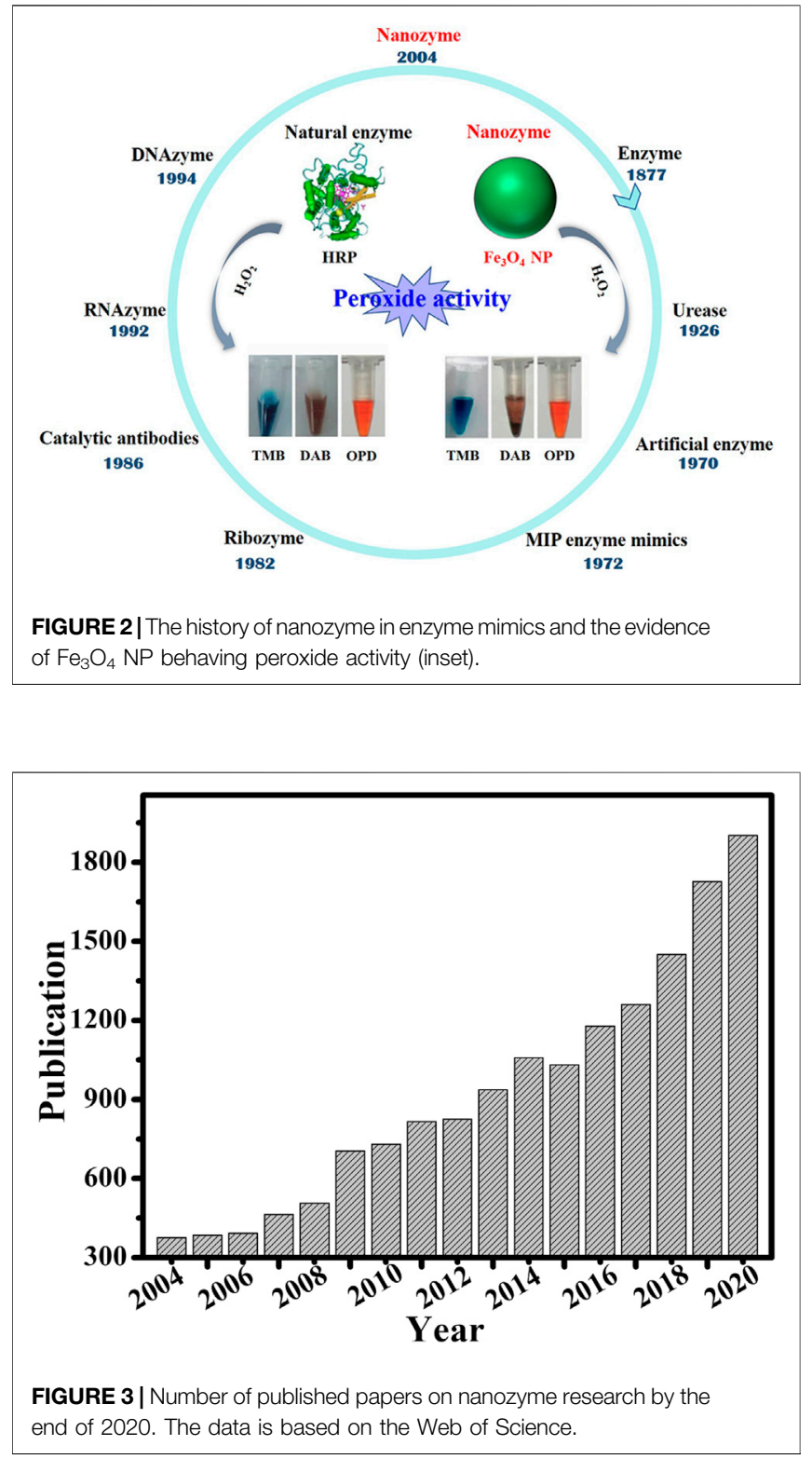

\section{HISTORY AND DEVELOPMENT}

Looking back at the first term "enzyme" coined by Wilhelm Kuhne in 1877, enzymes have gone for more than 120 years. Manea et al. described the transphosphorylation reactivity of triazacyclononane-functionalized $\mathrm{Au} \mathrm{NP}$, and the new term "nanozyme" was coined (Manea et al., 2004). Since then, the nanozymes have become a new member in field of enzyme mimics. Later, Gao et al. discovered that $\mathrm{Fe}_{3} \mathrm{O}_{4} \mathrm{NP}$ has good enzyme-mimicking activity, which opens up a broad range of applications (Gao et al., 2007). Now, it is known that nanozymes are nanomaterials with intrinsic enzyme-like characteristics. The development and evidence of nanozymes behaving peroxide activity are shown in Figure 2. Given advantages like low cost, recyclable utilization, high catalytic activity, and stability, 


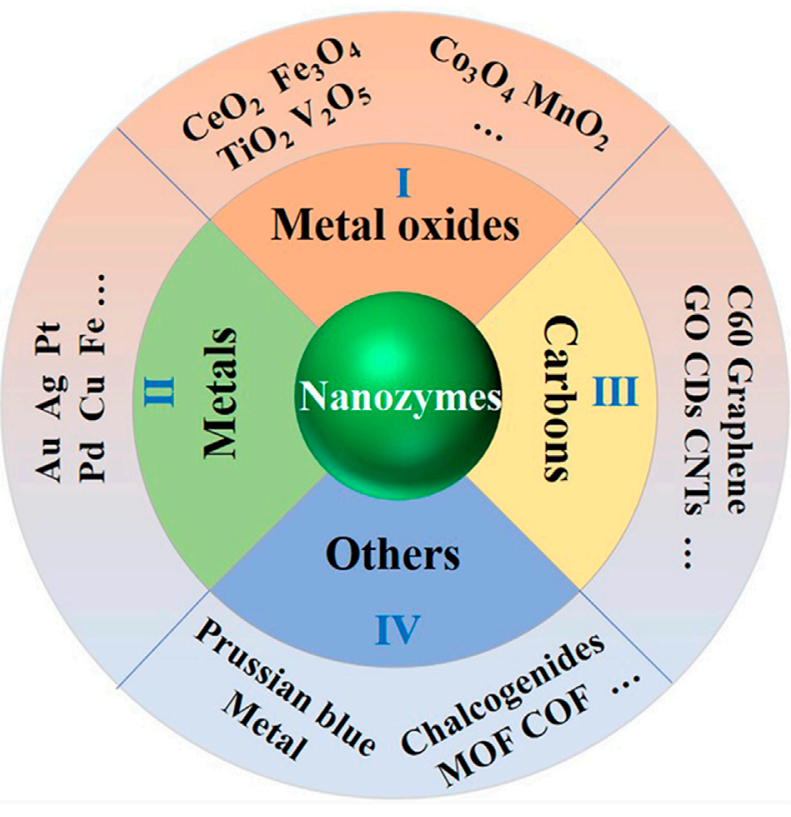

FIGURE 4 | Schematic presentation of nanozymes classifications (metal-, metal oxide-, and carbon-based nanozymes and other nanozymes like MOF, COF, etc.).

nanozymes are expected to be the next-generation artificial enzymes (II).

In recent decades, more than 200 research groups around the world have been studying nanozymes (Liang and Yan 2019). However, the activity descriptors of the nanozymes still remain largely unknown. Enormous efforts have been devoted to exploring nanozymes covering hundreds of nanomaterials. Dramatic growth has been witnessed for nanozymes research in catalysis, analytical techniques, environmental science, biomedical diagnosis, bioimaging, and antibacterial agents, suggesting their scientific significance and application prospects (Figure 3).

\section{CLASSIFICATION}

\section{Classification}

Generally, nanozymes can be classified as four groups according to the components, that is, metallic-based, metal oxide-based, carbon-based, and other nanozymes (Figure 4). Metallic-based nanozymes include metal nanoparticles, such as gold nanoparticles (Au NP), platinum nanoparticles (Pt NP), and palladium nanoparticles (Pd NP). To enhance their catalase activity, some bimetallic nanozymes include Au@Pt, Pt@Pd, and Au@Ag that are developed (Nandhakumar et al., 2020). Even ternary metallic nanozymes like AgAuPt NP and PtPdAu NP were explored. Despite their advantages like being easy to be prepared and modified, metallic-based nanozymes may suffer from disadvantages including metal toxicity and spontaneous aggregations.
Unlike metal-based nanozymes, metal oxide-based ones possess abundant groups with different functions. For example, $\mathrm{Fe}_{3} \mathrm{O}_{4}$ nanozymes can be used as peroxidase-, catalase-, or oxidase-like enzyme, and $\mathrm{CeO}_{2}$ nanozymes can act as superoxide dismutase, catalase-, and oxidase-like enzymes (Nicolini et al., 2015). In addition, there are many other metal oxide-based nanozymes, such as $\mathrm{CuO} \mathrm{NP}, \mathrm{MnO}_{2}$ $\mathrm{NP}, \mathrm{V}_{2} \mathrm{O}_{5} \mathrm{NP}$ (Yang F. et al., 2018), and so on. With the aid of surface functional groups, metal oxide-based nanozymes are more stable and easier to be modified.

Carbon-based nanozymes mainly include carbon nanotubes $(\mathrm{CNT})$, graphene oxide $(\mathrm{GO})$, and carbon nanodots, which were known as carbon-based nanozymes (Garg and Bisht 2016). For example, Cui has developed a combined hydrothermal/hydrogen reduction method for mass production of spiral carbon nanotubes by pyrolysis of acetylene (Cui et al., 2011). Early in 2009, Wang et al. described an electrochemiluminescence (ECL) sensor based on CdS nanocrystals formed on the surface of multiwalled carbon nanotubes (CdS/MWCNT) (Wang et al., 2009). With the peroxidase-like activity of MWCNT, CdS/ MWCNT can react with $\mathrm{H}_{2} \mathrm{O}_{2}$ to generate strong and stable ECL signals. Such examples can be found in many other applications like environmental engineering or even synthetic chemistry (Sun et al., 2018).

Recently, a variety of new nanomaterials have been found to mimic the activity of enzymes, such as metal-organic frameworks (MOFs), covalent organic frameworks COFs, and Prussian blue (PB) (Zhou et al., 2020). Because of its porosity and large specific surface area and the diversity of structures and functions, MOFs have been widely concerned and applied in a number of crucial sensing, energy, and catalysts domains, including toxins detection, gas storage and separation, and electrocatalysis (Lustig et al., 2017; Li et al., 2018). For example, Zhou et al. report the first chiral nanozyme based on mimicking a natural enzyme and the superior structure of COFs, which showed higher activity than the natural enzyme (Zhou et al., 2020). Li et al. developed a new kind of microelectrode for in vivo monitoring of $\mathrm{H}_{2} \mathrm{O}_{2}$ by electrodeposition of $\mathrm{PB}$ onto CNTs assembled carbon fiber microelectrodes (Li et al., 2016). All the methods are based on the excellent properties of the newly developed nanozymes.

\section{Functions and Performances}

As a specific kind of artificial enzymes (II), nanozymes behave desirable functions beyond catalysis. For example, from metal to metal oxides, then to carbon, a variety of sources can be provided to synthesize nanozymes, which make them readily available. Many nanozymes exhibit multienzymes functions by mimicking different kinds of natural enzymes. For example, depending on $\mathrm{pH}, \mathrm{CeO}_{2} \mathrm{NP}$ and $\mathrm{Au} \mathrm{NP}$ can exhibit superoxide dismutase, peroxidase, and catalase activities, which is mainly dependent on their kinetic characterization (Wu et al., 2019c). Usually, Michaelis-Menten kinetics experiments are carried out to compare with those natural enzymes. By this means, the standards in terms of the substrate specificity $(\mathrm{Km})$, catalytic rate constant (kcat), and catalytic efficiency $(\mathrm{kcat} / \mathrm{Km})$ can be united. 


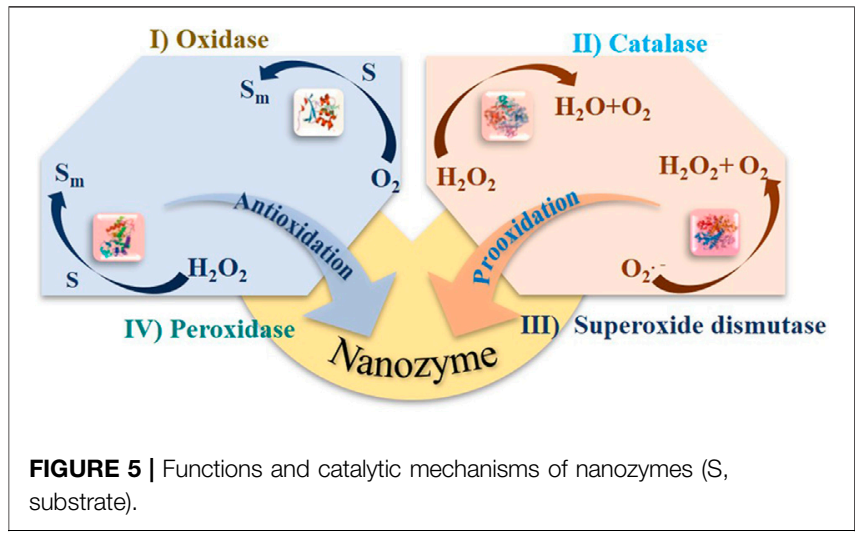

In general, nanozymes have the oxidase-, hydrolase-, superoxide dismutase-, and catalase-mimicking activity (Figure 5). The catalytic mechanisms and kinetics have been widely discussed regarding conditions like $\mathrm{pH}$, temperature, or even dissolved oxygen. However, as mentioned above, several different functions can be found in one type of nanomaterial, which are $\mathrm{pH}$ dependent or related to structural properties (size, morphology, surface groups, defects, etc.). Due to the complex interdependence between physicochemical properties and catalytic characteristics, a guide is needed to engineer and design nanozymes.

\section{ENGINEERING AND MODIFICATION}

Many studies have revealed that the structural properties like size, morphology, and surface groups are vital contributors to the catalytic activity of nanozymes (Liu and Liu 2017; Jiao et al., 2019). Typically, the specific surface area of nanoparticles increases as their size decreases, which result in a serious shortage of coordination number of surface atoms. Therefore, the surface active sites increased, and the catalytic efficiency is enhanced. That is, the smaller the nanozymes are, the higher their catalytic activity is. In this regard, the enzyme activity can be adjusted by controlling the size.

Besides, during the reaction process, the morphology and interface structure of nanozymes may change with different reaction conditions and thus have effects on the catalytic performance (Vernekar et al., 2016). By selectively exposing the crystal surface with high activity or specific energy, the catalytic activity of nanoparticles can be improved a lot (Kuang et al., 2014). The morphology-dependent nanozymes can be ascribed to the different lattice arrangement of atoms with different appearance structures, which lead to different surface activity and catalytic performances.

What is more, the functions of nanozymes can be reformed via a variety of surface modification means (charges, coatings, functionalization, and loadings). Based on this, both target recognition and target-dependent catalytic activities can be achieved by surface engineering strategies. Such successful modification examples include ions (Huang et al., 2019c), small molecules (Chang et al., 2016), nucleotides and nucleic acids (Huang et al., 2018a), amino acids and peptides (Fan et al., 2017), proteins (Su et al., 2019), and polymers (Wu Y. et al., 2019) (Figure 6). The operation can strengthen the functions of nanozymes and extend their applications. Specifically, those nanozymes with unique surface can realize sensitive and specific recognition and detection of analytes.

\section{APPLICATION IN FOOD CONTAMINANTS DETECTION}

Since food contaminants have posed great threat to human health and also show huge risks in food safety, it is essential to develop analytical methods for analyzing food contaminants for food safety supervision and risk assessment. Nevertheless, it remains great challenge to achieve rapid detection of food contaminants, and there are still some technical limitations to be solved. The development of cost-effective, rapid response, high sensitivity, and selectivity detection method for toxins has significant market prospects and huge social benefits. Taking advantage of the physiochemical properties of nanozymes, they are supposed be a potential candidate in improving the performance of analytical methods.

In this section, different classes of food contaminants are first introduced, including toxins, pesticide residues, food additives abuse, and microorganism, as well as their application and properties. Next, nanozymes-based analytical methods are carefully discussed to prove the good detection performance, especially for food contaminants with certain limit quantity. Immunoassays, a system based on biochemical recognition that can sensitively convert concentrations of analytes into signals, are introduced in food contaminants detection.

\section{Toxins}

A toxin can be something produced by an organism that interferes with the action of other lives and cause poisoning in human body (Harms et al., 2018). Trace amount of the toxins in human body can cause biological damage, even resulting in death. For example, mycotoxins are secondary metabolites produced by some fungi (mainly Aspergillus, Penicillium, and Fusarium) during the growth, which can easily cause physiological abnormalities in humans and animals (Zain 2011). The mycotoxins can enter the food chain through contaminated grains or the products of animals (e.g., milk, meat, and eggs) that were fed with mycotoxin-contaminated feed. To ensure food safety and guarantee the human health, it is of great significance to develop powerful methods to monitoring the trace level of toxins in food samples (Figure 7).

\section{Detection of Mycotoxins}

The most common mycotoxins are aflatoxin, ochratoxin, fumonisin, zearalenone patulin, and deoxynivalenol. Due to their toxicological effects, the presence of mycotoxins in foods has severe implications on human and animal health even at very low concentration level (Cimbalo et al., 2020). Thus, it is essential to develop rapid methods for the detection of these mycotoxins in food products. For instance, based on $\mathrm{CdTe} / \mathrm{CdS} / \mathrm{ZnS}$ quantum 


\section{Inorganic ions}

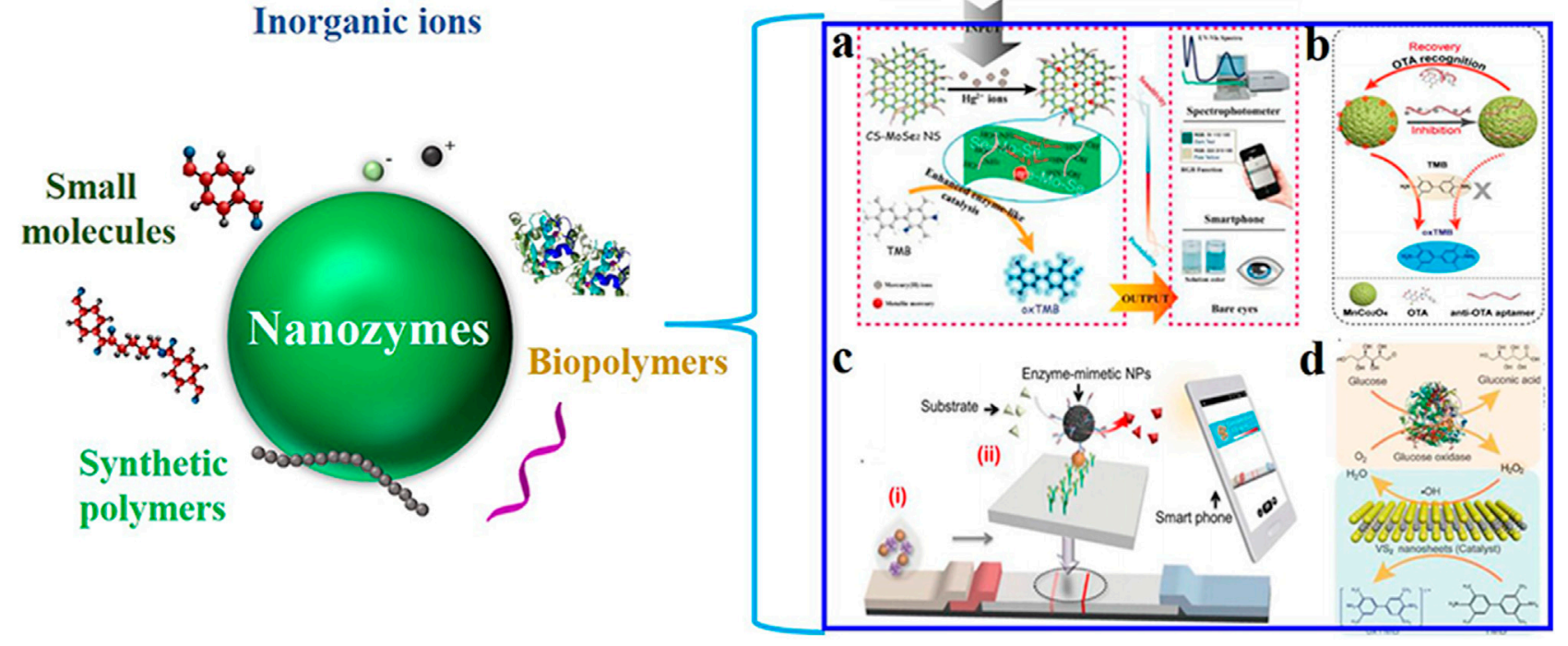

FIGURE 6 | Modification of nanozymes and their application in constructing analytical techniques ((a): Huang et al., 2019b; (b) Huang et al., 2018a; (c) Kim et al., 2015; (d) Huang et al., 2018b).

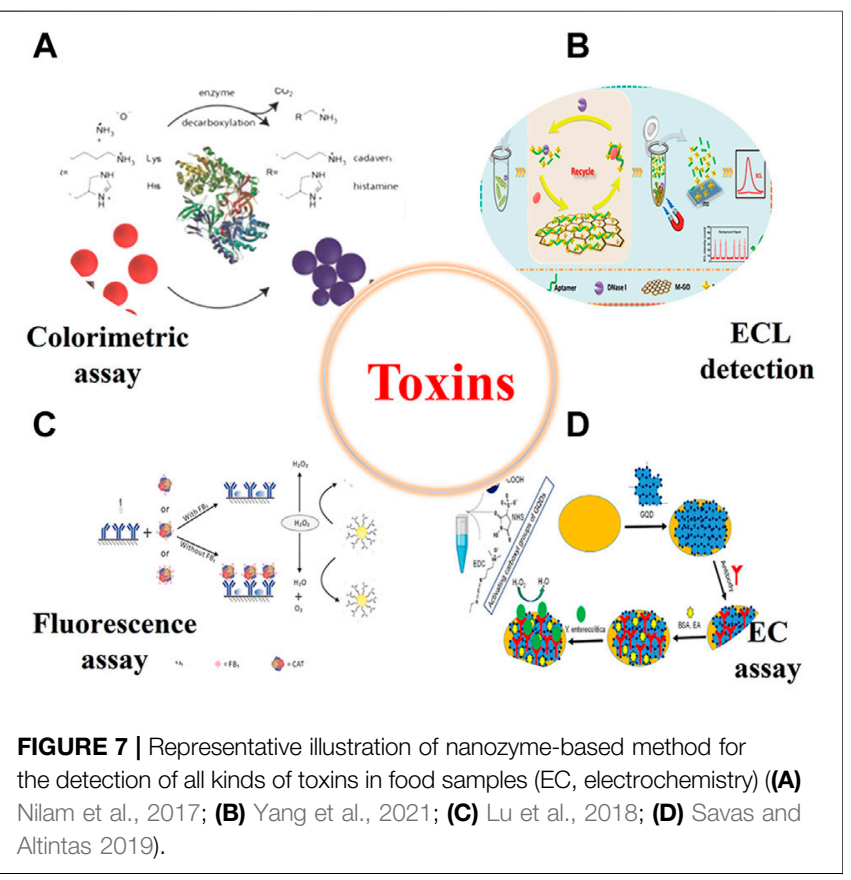

dots, luminol, and HRP-modified gold nanorods, Wu et al. designed a ratiometric ECL aptasensor for AFB1 detection (Wu et al., 2017). The ratiometric aptasensors exhibited accurate and sensitive analytical performance for AFB1 with a good linear range from $5.0 \mathrm{pM}$ to $10 \mathrm{nM}$ with a LOD of $0.12 \mathrm{pM}$. The nanozymes-based immunosorbent assay has proved the superior performance of nanozymes in enhancing the detection sensitivity. Based on mesoporous $\mathrm{SiO}_{2} / \mathrm{Au}-\mathrm{Pt}$ (m-SAP), an aptamer, and $\mathrm{Fe}_{3} \mathrm{O}_{4}$ magnetic nanoparticles (MNP), a nanozyme and aptamer-based immunosorbent assay
(NAISA) was constructed for AFB1 detection (Wu et al., 2020a). In the work, m-SAP were prepared to act as signal labels, aptamer was adopted to recognize AFB1, and MNP facilitated to realize magnetic separation. The NAISA method showed a LOD of $5 \mathrm{pg}$ $\mathrm{ml}^{-1}$, which is 600 -fold lower than that of traditional ELISA method. Further, based on Au NPs-assisted triple cascade signal amplification, Hong et al. proposed a magnetic relaxing sensing method for the detection of AFB1 with a LOD of $0.453 \mathrm{pg} \mathrm{ml}^{-1}$ (Hong et al., 2021). Xu et al. reported an indirect competitive MOF-linked immunosorbent assay for AFB1, which overcome the low catalytic activity and poor stability of natural enzymes with 20-fold enhancement in sensitivity (Xu et al., 2021). Obviously, nanozyme-based detection techniques can greatly improve the sensitivity with specific structural properties and excellent catalytic activity.

\section{Detection of Bacterial Toxins}

Besides, the detection of bacterial toxins like Escherichia coli toxin, enterotoxins, and botulinum neurotoxins is discussed. For example, Ching et al. described the use of Au NP in a single lateral flow device for detection of botulinum neurotoxins A and B (Ching et al., 2012). If toxin is present, it binds with the goldconjugated antibody and together flow to the test capture line, resulting in the resolution of a red line. This is a typical lateral flow immunoassay that can be extended to nanozymes-based analytical techniques. Shlyapnikov et al. reported a microarraybased immunoassay for the simultaneous detection of five bacterial toxins, including cholera toxin, E. coli heat-labile toxin, enterotoxins, and the toxic shock syndrome toxin (Shlyapnikov et al., 2012). The assay can be completed in less than 10 min with the LOD low to $0.1-1 \mathrm{pg} \mathrm{ml}^{-1}$ for water and to $1 \mathrm{pg} \mathrm{ml}^{-1}$ for food samples. Few nanozymes-based analytical techniques have been fabricated for the detection of bacterial toxins. However, nearly all the immunoassays involve the 
reaction of enzyme and $\mathrm{H}_{2} \mathrm{O}_{2}$, so it can be a creative way to apply nanozymes in the previously reported immunoassay by replacing the enzyme conjugated antibody.

\section{Detection of Marine Toxins}

Marine biotoxin is a kind of highly active special metabolic component in marine organisms, which can severely affect human health, economy, wildlife, and ultimately the ecosystem (Bano et al., 2020). By immobilizing BTX-2-bovine serum albumin conjugate on Au NP-decorated poly(amidoamine) dendrimers, Tang et al. developed an electrochemical assay for the fast screening of brevetoxin B (BTX-2) in food samples (Tang et al., 2011). The application of $\mathrm{Au} \mathrm{NP}$ can improve the conductivity of dendrimers on the electrode. The BTX-2 assay was conducted with a competitive immunoassay using HRPlabeled anti-BTX antibodies and $\mathrm{H}_{2} \mathrm{O}_{2}-O$-phenylenediamine (OPD) reaction system. The method behaved a wide linear range of $0.03-8 \mathrm{ng} \mathrm{ml}^{-1}$ with a LOD of $0.01 \mathrm{ng} \mathrm{ml}^{-1}$. Based on a double-integrated mimic enzyme formed by $\mathrm{Cu}(\mathrm{OH})_{2}$ nanozyme and G-quadruplex/hemin DNAzyme, Liu et al. established an immunosensor for detection of microcystin-LR (Liu T. et al., 2019). In the strategy, $\mathrm{Cu}(\mathrm{OH})_{2}$ nanozyme acted as labels to capture the secondary antibody as well as a substrate for loading DNAzymes. The method had high activity for the ABTS chromogenic reaction, which realized the visual detection of microcystin-LR in the range from 0.007 to $75 \mu \mathrm{g} \mathrm{L}{ }^{-1}$ with a LOD of $6 \mathrm{ng} \mathrm{ml}^{-1}$. Such double-integrated artificial enzyme showed a stable and catalytic ability to $\mathrm{H}_{2} \mathrm{O}_{2}$ and ABTS, further revealing the superiority of functional nanozymes.

\section{Detection of Plant Toxins}

Plant toxins, also known as phytotoxins, are secondary plant metabolites that have acute or chronic toxicity or pose antinutritional effects on people. The commonly detected that plant toxins include pyrrolizidine alkaloids, grayanotoxins, opium alkaloids, strychnine, ricinine, aconitine, aristolochic acid, and cardiac glycosides (e.g., digitoxin, digoxin). For example, $\mathrm{Hu}$ et al. proposed a sensitive colorimetric aptasensor for the quantitative detection of abrin using Au NP nanozyme (Hu J. et al., 2015). Au NP possesses the peroxidase-like activity that can catalyze TMB in the presence of $\mathrm{H}_{2} \mathrm{O}_{2}$ with color variations. The method behaved a linear range from 0.2 to $17.5 \mathrm{nM}$, with a LOD of $0.05 \mathrm{nM}$ for abrin. Velmurugan et al. reported the fabrication of $\mathrm{Co}(\mathrm{OH})_{2}$-enfolded $\mathrm{Cu}_{2} \mathrm{O}$ nanocubes on reduced graphene oxide (rGO) to develop an electrochemical caffeine sensor (Velmurugan et al., 2016). The nanozymes had a good electrocatalytic activity towards the determination of caffeine in beverage samples. The sensor showed a linear range from 0.83 to $1,200 \mu \mathrm{M}$ with a LOD of $0.4 \mu \mathrm{M}$. Furthermore, based on chitosan functionalized magnetic graphene oxide, Tang et al. developed an extraction method for efficient extraction and determination of alkaloids in hotpot (Tang et al., 2020). The study was carried out without using nanozymes. However, the detection was successfully conducted by the pretreatment of nanocomposites, which posed good guiding sense towards the nanozyme-based analytical techniques.

\section{Pesticide Residues}

Pesticides are one of the major inputs used in agriculture to protect crops and seeds before and after harvesting (Bajwa and Sandhu 2014). Though they have contributed huge economic benefits to society, the pesticide residues left in the food materials can have deleterious effect on human health (Jiang et al., 2008). Moreover, widespread use of pesticides has caused serious concerns in food safety, because the residues are easily exposed to primary and derived agricultural products. Thus, in order to ensure food safety for consumers, many countries and organizations around the world have established maximum residue limits (MRL) for pesticides in foods (Jallow et al., 2017).

On the other hand, due to the large amounts of pesticides currently being used, an increasing interest has been attracted for developing rapid screening systems to monitor their level in the food products (Liu W. et al., 2019). In this section, three kinds of pesticides include organophosphates (OPPs), neonicotinoids (NNOs), and triazines (TAs) that are introduced as analytes (Figure 8). To achieve robust detection of pesticides, several analytical techniques based on nanozymes are developed and highlighted.

\section{Analysis of Organophosphates Pesticides}

Among the toxic pesticides, organophosphorus pesticides (OPPs) have been reported as the major contaminants in the water, fruit, or medicinal plants (Yang Q. et al., 2018). For example, Wei et al. proposed a dual-mode strategy using nanoceria as nanozyme for methyl-paraoxon (MP) analysis (Wei et al., 2019). Based on the enzyme-like activity of nanoceria, MP could be hydrolyzed to para-nitrophenol (p-NP) with bright yellow color and characteristic absorption peak, which can be easily analyzed by the colorimetric and spectroscopic techniques. Both strategies showed LODs of $0.42 \mu \mathrm{M}$. To detect omethoate and dichlorvos and, at the same time, evaluate the activity of acetylcholinesterase (AChE), Huang et al. proposed a colorimetric paper sensor using $\gamma$-MnOOH nanowires (NWs) as nanozyme and $3,3^{\prime}, 5,5^{\prime}$ tetramethylbenzidine (TMB) as a chromogenic indicator (Huang et al., 2019a). The concentration of pesticides and AChE activity can be measured by the changes in absorbance at $652 \mathrm{~nm}$ or blue color of oxidized TMB products. The paperbased test had LODs of $0.1 \mathrm{mU} \mathrm{mL}^{-1}$ for AChE, $10 \mathrm{ng} \mathrm{ml}^{-1}$ for omethoate, and $3 \mathrm{ng} \mathrm{ml}^{-1}$ for dichlorvos.

\section{Analysis of Neonicotinoid Pesticides}

Neonicotinoid pesticide is a relatively new group of active ingredients with broad spectrum systemic action, low toxicity, and high insecticidal efficiency to mammals (Wu et al., 2020b). Weerathunge et al. reported a colorimetric assay for rapid detection of acetamiprid with acetamiprid-specific aptamer and $\mathrm{Au}$ NP nanozyme (Weerathunge et al., 2014). This approach can realize detection of $0.1 \mathrm{ppm}$ acetamiprid within $10 \mathrm{~min}$. Based on an aptamer against acetamiprid, multiple complementary strands (CSs), and gold nanoparticles ( $\mathrm{Au}$ $\mathrm{NP}$ ), a fluorometric assay was developed for the selective detection of acetamiprid (Bahreyni et al., 2018). The method can realize the detection of acetamiprid in a range of 5-50 nM with a LOD of $2.8 \mathrm{nM}$. In this work, apart from the nanozyme 


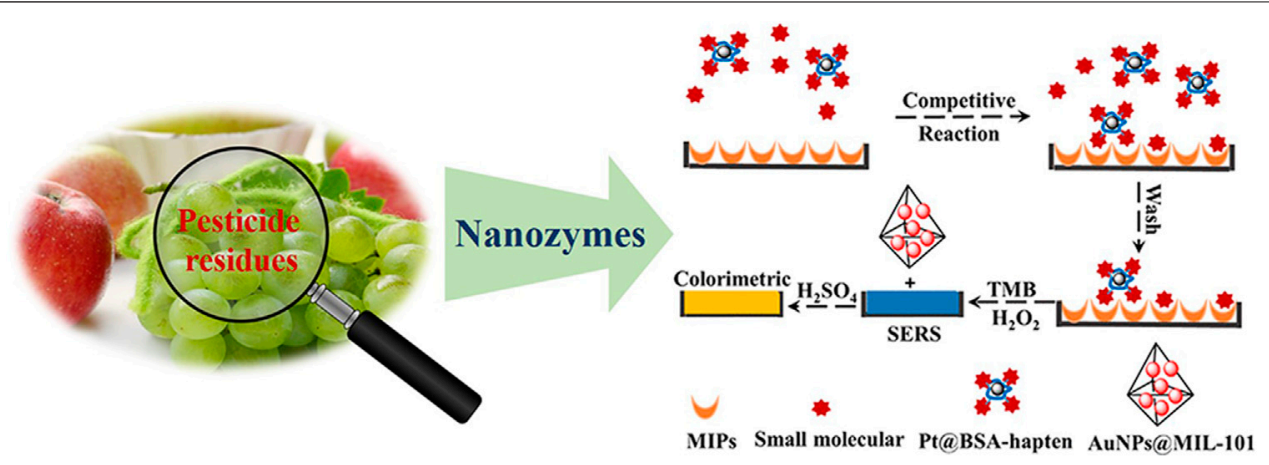

FIGURE 8 | Representative illustration of nanozyme-based method for the detection of all kinds of pesticide residues in food samples (Yan et al., 2019).

activity of $\mathrm{Au} \mathrm{NP}$, their quenching effect toward specific fluorescent materials was applied in analytical methods.

\section{Analysis of Triazine and Other Pesticides}

Once introduced into the crops, triazine pesticides can cause long-term negative effects due to their persistence. Another issue is their easy distribution into other parts of the environment, especially from soil into groundwater, one of the main sources of drinking water. Thus, it is a vital subject to develop analytical techniques of triazine pesticides by easy and cost-effective techniques in environmental chemistry.

Boruah and Das prepared $\mathrm{Fe}_{3} \mathrm{O}_{4}$ - $\mathrm{TiO}_{2}$ /reduced graphene oxide $\left(\mathrm{Fe}_{3} \mathrm{O}_{4}-\mathrm{TiO}_{2} / \mathrm{rGO}\right)$ nanocomposite with hydrogen peroxide activity and photocatalytic efficiency (Boruah and Das 2020). The colorimetric detection technique is applied for the sensing of atrazine using TMB as substrate molecules, which showed a LOD of $2.98 \mu \mathrm{g} \mathrm{L}^{-1}$ and a linear range of 2-20 $\mu \mathrm{g} \mathrm{L}^{-1}$. Based on a competitive ELISA, Kwon et al. developed peroxidaselike mesoporous core-shell palladium@platinum (Pd@Pt) nanoparticle conjugated primary antibody as enzyme labels to detect atrazine (Kwon et al., 2020). The method leads to a high sensitivity with a LOD of $0.5 \mathrm{ng} \mathrm{ml}^{-1}$ and recoveries of $99-115 \%$, demonstrating that atrazine and other herbicides and pesticides can be detected using this immunoassay. With the help of heteroatom-doped grapheme, Zhu et al. fabricated a colorimetric nanozyme sensor arrays for detection of the aromatic pesticides via the $\mathrm{TMB} / \mathrm{H}_{2} \mathrm{O}_{2}$ system ( $\mathrm{Zhu}$ et al., 2020a). Five different pesticides like fluroxypyr-meptyl, lactofen, diafenthiuron, bensulfuron-methyl, and fomesafen were successfully detected from 5 to $500 \mu \mathrm{M}$. Obviously, the inhibition effect of pesticides toward natural enzyme is also suitable for nanozyme, which can be effectively used to indicate the quantity of pesticides combining with $\mathrm{TMB} / \mathrm{H}_{2} \mathrm{O}_{2}$ coloring system.

\section{Veterinary Drug Residues}

Veterinary drugs are a kind of substances, including pharmaceutical feed additives, which are often used to prevent, treat, and diagnose animal diseases or to purposely regulate animal physiological functions (Stolker and Brinkman 2005; Rocca et al., 2017). All veterinary drugs used in edible animals

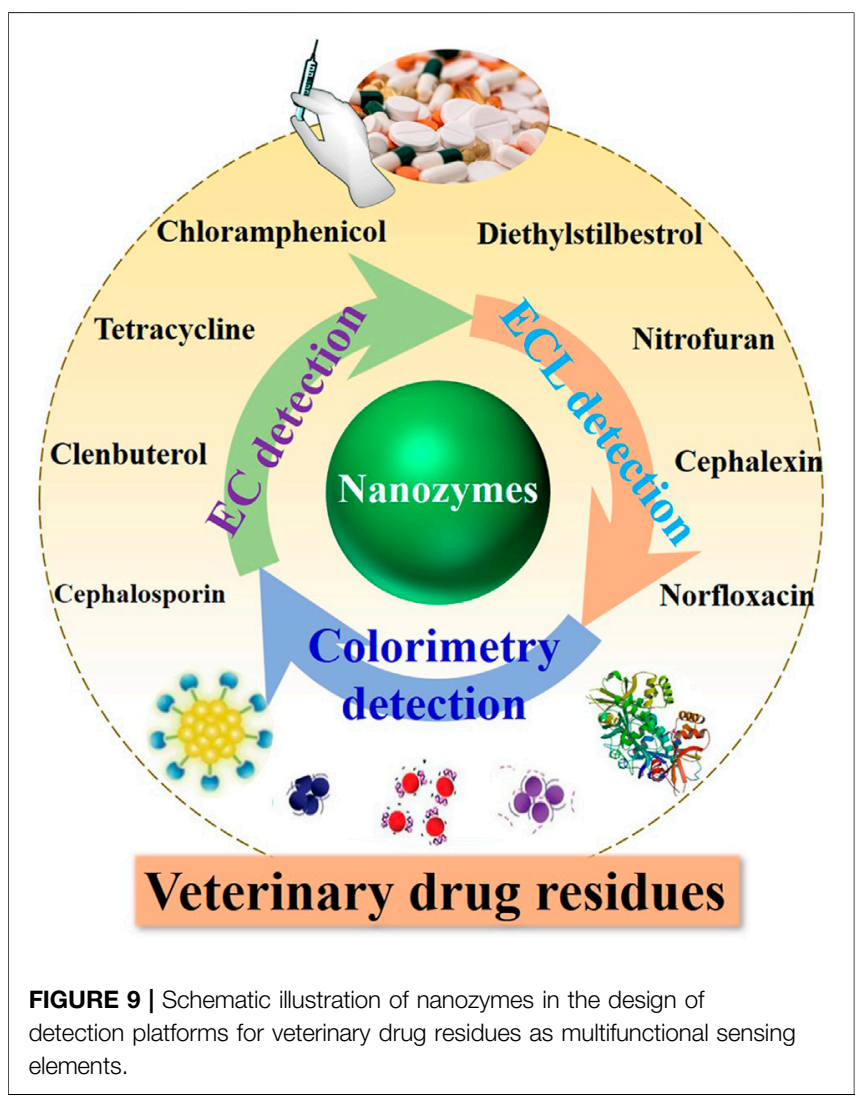

may cause residues in eggs, milk, and meat, which may contain parent compounds and metabolites or/and conjugates, and enter the human body via the food chain to produce direct toxic effects (Figure 9). Based on their functions, veterinary drugs can be classified as different groups such as antibiotics, anthelmintics, growth promoters, antiprotozoal drugs, trypanosomiasis drugs, sedatives, $\beta$-adrenergic receptor blockers, and so on (Winckler and Grafe 2001). The abuse of veterinary drugs can both cause direct harm to human health and the development of animal husbandry and the ecological environment (Masia et al., 2016). Therefore, it is critical to develop effective and rapid detection methods to screen food samples with veterinary drug residues. 


\section{Analysis of Antibiotics}

Based on the peroxidase-like activity of gold nanoclusters $(\mathrm{Au}$ $\mathrm{NC}$ ), Zhang et al. established a $\mathrm{TMB} / \mathrm{H}_{2} \mathrm{O}_{2}$ colorimetric sensing method for tetracycline antibiotics (TCs) via TCs-specific aptamers (Apt) (Zhang et al., 2020). The sensor can accurately and reproducibly detect tetracycline in drugs and milk in the range from 1 to $16 \mu \mathrm{M}$ with a LOD of $46 \mathrm{nM}$. In addition, Tian et al. established a ratio electrochemical biosensor for the quantitative detection of kanamycin based on signal amplification elements of planar $\mathrm{VS}_{2} / \mathrm{AuNP}$ nanocomposites and $\mathrm{CoFe}_{2} \mathrm{O}_{4}$ nanozyme (Tian et al., 2020). The electrochemical aptasensor revealed a detection range from 1 $\mathrm{pM}$ to $1 \mu \mathrm{M}$ with a LOD of $0.5 \mathrm{pM}$. Two main nanozyme-based analytical methods were introduced here. The first method is the colorimetric assay, which uses enzyme-mimic activity of nanozyme to produce color variations that can qualitatively determine analyte concentrations or adopt an instrument to quantitatively detect analytes. The other one is electrochemical assay, and nanozymes were used to catalyze TMB and generate oxidized species like oxidized TMB (oxTMB), behaving obvious characteristic signals for further analysis.

\section{Analysis of Antibacterial}

Antibacterial drugs are a class of drugs that can treat or prevent infectious animal diseases by inhibiting or killing the pathogenic bacteria. However, the abuse of such drugs can pose harmful effects on human health and the environment (Devasahayam, Scheld, and Hoffman 2010). Thus, various analytical methods have been developed for antibacterial drugs analysis. For instance, based on gold nanoclusters, Song et al. proposed a peroxidase-like activity enhancement assay for norfloxacin (Song et al., 2020). The linear relationship of norfloxacin monitoring was gained in the range of $1.25-8.0 \mu \mathrm{M}$ with a LOD of $0.2 \mu \mathrm{M}$. In addition, He et al. constructed a biomimetic nano-enzyme-linked immunosorbent assay for sulfadiazine detection using Au@ $\mathrm{SiO}_{2}$ nanoparticles labeling as markers (He J. et al., 2020). The method showed good stability with a LOD of $0.2 \mathrm{mg} \mathrm{L}^{-1}$ and recoveries from 78.00 to $90.96 \%$ in beef samples. Moreover, based on molecularly imprinted polymers and $\mathrm{Cu}(\mathrm{II})$ anchored unzipped covalent triazine framework, $\mathrm{Ma}$ et al. described an ECL assay for sulfa quinoxaline (SQX) using the luminol/ $\mathrm{H}_{2} \mathrm{O}_{2}$ system (Ma et al., 2018). The method achieved good performance with a detection range of $1.0-20 \mathrm{pM}$ and a LOD of $0.76 \mathrm{pM}$.

\section{Analysis of Other Drugs}

Other types of veterinary drugs like antiviral drugs and hormones are also easy to contaminate animal foods. Excessive use of these antiviral drugs will inevitably lead to drug residues in animals and eventually enter the human body via the food chain. Therefore, it is very meaningful to construct rapid method for detection of veterinary drug residues. For example, Ma et al. developed a colorimetric immunoassay for the detection of amantadine by introducing nanocube Pt as nanozyme labels (Ma et al., 2018). According to this protocol, antiviral drugs like amantadine can be detected with the sensitivity of $0.195 \mathrm{ng} \mathrm{ml}^{-1}$ for naked eyes and $0.134 \mathrm{ng} \mathrm{ml}^{-1}$ for optical detection. The proposed method not only outcompeted reported methods, but greatly improved the naked-eye and optical measurements as compared with conventional signal-off immunoassays.

\section{Pathogens}

Foodborne pathogenic microorganisms have attracted intensive attention in food safety, which can make bacteria in food multiply and even produce a large number of toxic metabolites. Poisoning accidents caused by mistakenly eating polluted foodstuff frequently occur. Traditional techniques suffered from limitation of low sensitivity, complex procedures, and timeconsuming operations. Emerging analytical methods based on nanozymes have been widely developed, which make pathogens easier to be detected. In this section, various nanozyme-based assays for foodborne pathogens are described, involving colorimetric assay, lateral flow immunoassay, electrochemical assay, and so on (Figure 10).

\section{Bacteria}

Bacteria are the main categories of foodborne pathogens, including E. coli, Salmonella, Listeria, S. aureus, Shigella, S. haemolyticus, and V. parahaemolyticus. Among them, E. coli O157:H7 (E. coli) is a highly infectious pathogen that spreads widely in food and water and poses a major challenge to public health. Therefore, there is an urgent need to develop a new rapid method for detection of foodborne pathogens.

For example, Fu et al. proposed a two-step cascade signal amplification strategy for detection of $E$. coli, which combines in situ gold growth with nanozyme-catalyzed deposition and greatly improves the sensitivity of conventional gold lateral flow assay (Au NP-LFA) (Fu et al., 2020). The in situ engineering of nanozyme method achieved an ultrahigh LOD of $12.5 \mathrm{CFU} \mathrm{ml}{ }^{-1}$, 400-fold enhancement compared with that of traditional Au NP-ICA. Han et al. prepared palladium-platinum (Pd-Pt) nanoparticles as enzyme probes to establish a sensitive LFA for detection of E. coli (Han et al., 2018). By using TMB substrate onto the test line, the assay exhibited an enhanced sensitivity of $9.0 \times 10^{2} \mathrm{CFU} \mathrm{ml}{ }^{-1}$ in milk, which was 111-fold higher than that of traditional Au NPICA. To get over the shackles of traditional LFA and build a flexible model, increasing studies have been carried out to develop a label-free and low-cost LFA, in which functional nanozymes are widely adopted to replace enzyme labeled antibodies and act as effective recognition agents to generate signals (Cheng et al., 2017; Liu et al., 2018; Wang H. et al., 2020; Liu, Wang, et al., 2020). According to previous reports, the colorimetric assay can become a versatile strategy for rapid detection of a wide variety of other bacteria and pathogens. Moreover, Zhang et al. designed a MOF@COF nanozyme to perform enhanced inhibition of bacteria like E. coli and $S$. aureus, which demonstrate the possibility of nanozymes using as potential antibacterial agents (Zhang et al., 2021). No matter in detections or antimicrobial applications, active centers, hierarchical nanocavities, and pore microenvironment within nanozymes always play important roles in their efficient catalytic activity. 


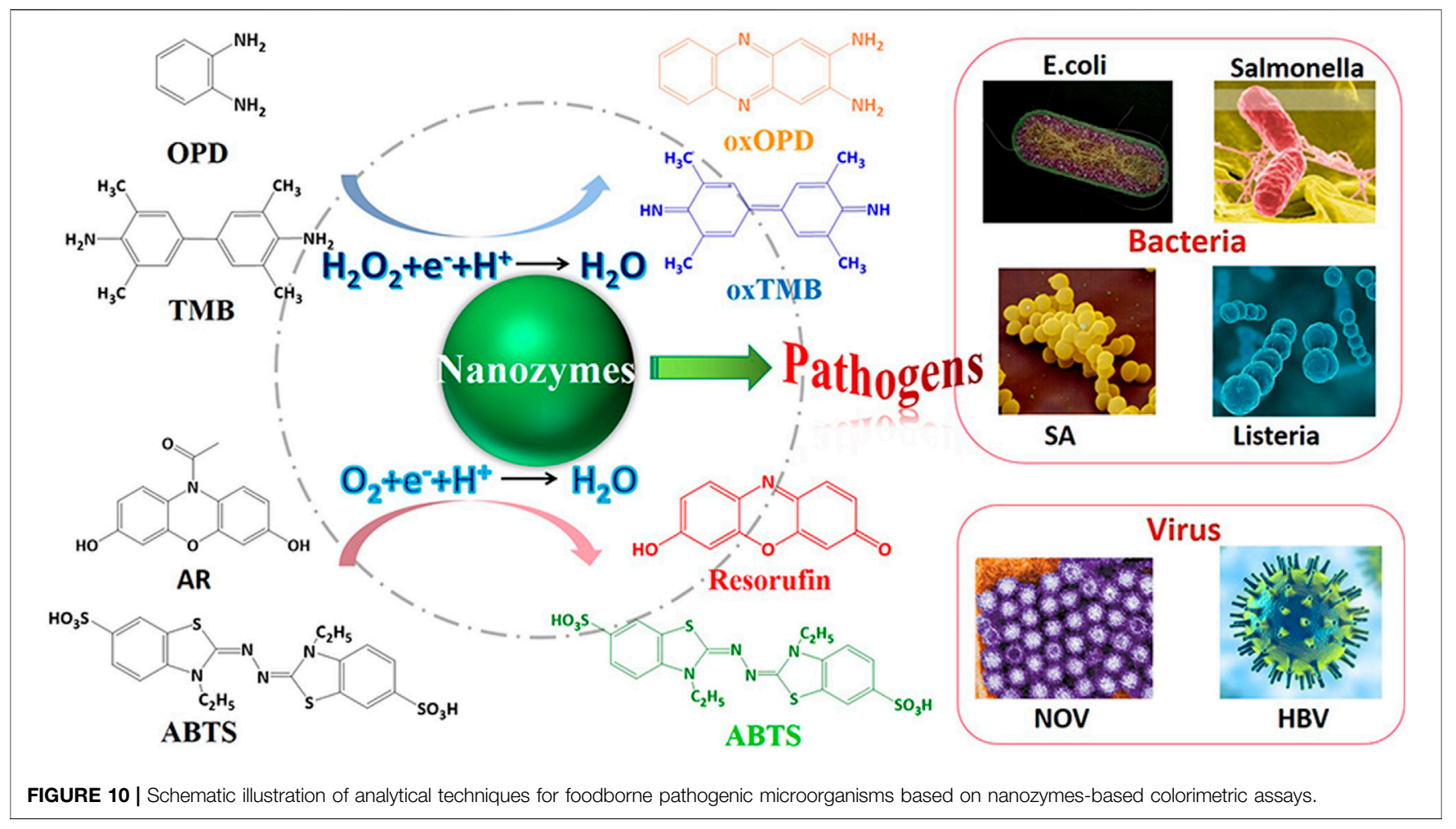

\section{Viruses}

Apart from bacteria, viruses belong to foodborne pathogenic microorganisms that may contaminate the foods. However, a lack of knowledge about the viruses in food safety issues is reported. At present, the common foodborne viruses mainly include hepatitis A and hepatitis E viruses, rotavirus, astrovirus, enterovirus, and norovirus. Human norovirus $(\mathrm{NoV})$ is one of the most common viruses that cause foodborne outbreaks worldwide (Patel et al., 2009). For example, based on the peroxidase activity of silver ionincorporated $\mathrm{Au} \mathrm{NP}$ (Au/Ag NP), Khoris et al. developed a colorimetric bioassay for detection of NoV (Khoris et al., 2019). Simply, NoV was captured by anti-NoV genogroup II antibodies and formed a sandwich structure with antibody modified $\mathrm{Au} \mathrm{NP}$. The in situ growth of $\mathrm{Au} / \mathrm{Ag}$ was controlled by introducing $\mathrm{Ag}^{+} /$hydroquinone solution. When $\mathrm{TMB} / \mathrm{H}_{2} \mathrm{O}_{2}$ was added to the wells, Ag ions were released from the surface of $\mathrm{Au} / \mathrm{Ag}$ NPs and enhanced the oxidation of TMB with an intense blue color. The method showed a LOD of $13.2 \mathrm{c} 132$ copies/g feces in the range of $10^{2} \sim 10^{6}$ copies of viral $\mathrm{RNA} / \mathrm{mL}$. The strategy offers an alternative for practical deployment of the norovirus detection with simple pretreatment in contaminated food.

\section{Food Additives}

Food additives are a kind of raw material added in food or in the process of food production, which aim to improve food edibility as well as the taste and aesthetic feeling of food. The excessive use of additives or illegal use of non-food additives will cause a series of food safety problems. High doses of food additives may have harmful longterm effects on animals such as cancer proliferation (Dolatabadi and
Kashanian 2010). Therefore, the analysis of these unavoidable additives in food samples is important. In this section, nanozymebased methods are discussed for the detection of food additives.

\section{Analysis of Antioxidants}

Antioxidants can prevent or delay food oxidation deterioration by reducing oxygen or free radical level around food and thus improve the stability and storage resistance. Many analytical procedures have been developed for the detection of antioxidants. In this part, nanozymes-based electrochemical and colorimetric assays are introduced to analyze antioxidants. For example, based on spiny $\mathrm{Au}-\mathrm{Pt}$ nanotubes and horseradish peroxidase, $\mathrm{Wu}$ et al. proposed an electrochemical biosensor for the simultaneous determination of butylated hydroxyanisole (BHA) and propyl gallate (PG) (Wu et al., 2016). The method showed a wide linear range of $0.3-50 \mathrm{mg} \mathrm{L}^{-1}$ and $0.1-100 \mathrm{mg} \mathrm{L}^{-1}$ for BHA and PG with LODs of $0.046 \mathrm{mg} \mathrm{L}^{-1}$ and $0.024 \mathrm{mg} \mathrm{L}^{-1}$. Moreover, BHA and PG were demonstrated by a simple visual detection method, which involved Au-Pt nanotubes, a kind of nanozymes, as catalyst and TMB as indicator. The combination of visual and electrochemical detection can greatly enhance the detection accuracy. In addition, Cui et al. designed and prepared a novel porphyrin-based porous organic polymer, which was adopted in the $\mathrm{TMB} / \mathrm{H}_{2} \mathrm{O}_{2}$ reaction system for the evaluation of antioxidants, like ascorbic acid (AA), gallic acid (GA), and tannic acid (TA) (Cui et al., 2018). The catalytic activity of nanozymes is also widely used in constructing electrochemical sensors. For instance, Yue et al. reported an electrochemical sensor for sensitive detection of TBHQ by integrating molecularly imprinted polymers (MIP), PdAu NP, and reduced graphene oxide (RGO) (Yue et al., 2019), wherein MIP realized the specific recognition with 
TBHQ, GRO accelerated electron transfer, and bimetallic PdAu NP acted as a promising catalyst.

\section{Analysis of Food Colorants}

Food colorants are dyes or pigments that impart color added to food or drink or any nonfood applications. Among them, synthetic ones like tartrazine, ponceau $4 \mathrm{R}$, allura red, and sunset yellow are widely used in food industry. However, continuous intake of synthetic ones may do certain toxicity to human body. Experiments demonstrated that a high dosage of the dye like amaranth might increase the incidence of malignant tumors in rats (El-Wahab and Moram 2013). So, the synthetic pigments allowed in some countries are regulated with strictly limited dosage. Nanozymes are popular in detecting colorants using the electrochemical sensors.

For example, based on $\mathrm{TiO}_{2} /$ electroreduced graphene oxide nanocomposites, Qin et al. described a voltammetric sensor for simultaneous detection of ponceau $4 \mathrm{R}$ and tartrazine (Qin et al., 2020). The method achieved the limit of detections (LODs) with 4.0 and $6.0 \mathrm{nM}$ for ponceau $4 \mathrm{R}$ and tartrazine, respectively. Similarly, $\mathrm{Li}$ et al. reported $\mathrm{TiO}_{2} / \mathrm{ErGO}$ nanohybrids for the electrochemical detection of allura red with enhanced electrocatalytic activity and voltammetric response, and the LOD is $0.05 \mu \mathrm{M}$ (Li et al., 2020). Besides, CuS with different morphologies was studied and then applied in tartrazine and sunset yellow detection by voltammetric techniques (Li et al., 2019). The CuS nanoflowers constructed electrode realized the detection limits of $12 \mathrm{nM}$ for tartrazine and $6 \mathrm{nM}$ for sunset yellow, revealing the unique electrocatalytic activities of CuS crystals.

\section{Analysis of Other Food Additives}

Other additives that are commonly detected include preservatives, sweetener, and flavor enhancers. For example, based on the peroxidase-like catalytic activity of nanozymes, $\mathrm{Xi}$ et al. designed copper/carbon hybrid as potential enzyme mimetics to generate ROS for antibacterial therapy (Xi et al., 2020). Based on $\mathrm{ZnO}$ NP/MWCNTs modified glassy carbon electrode, Balgobind et al. developed a differential pulse voltammetry (DPV) technique for aspartame detection (Balgobind et al., 2016). For the detection of preservatives, Rather et al. proposed an electrochemical detection of parabens by depositing polyaniline film (PANI) and $\mathrm{Au} \mathrm{NP}$ on the glassy carbon electrode. The square wave voltammetric response of ethylparaben (EP) shows a wide linear range from 0.1 to $5.10 \mathrm{nM}$ with a LOD of $0.1 \mathrm{nM}$. In addition, using gold nanoparticle decorated on a molybdenum disulfide/chitosan ( $\mathrm{Au} @ \mathrm{MoS}_{2} / \mathrm{Ch}$ ) as a conductive matrix, Devi et al. constructed an electrochemical immunosensor for the detection of monosodium glutamate, a kind of flavor enhancers (Devi et al., 2019). A linear detection range was perceived from 0.05 to $200 \mu \mathrm{M}$, with a LOD and limit of quantification (LOQ) of 0.03 and $0.1 \mu \mathrm{M}$, respectively.

\section{Heavy Metal lons}

Due to their potential threat to the public health, heavy metal ions $\left(\mathrm{Hg}^{2+}, \mathrm{Pb}^{2+}, \mathrm{Cd}^{2+}\right)$ in food has been of increasing concerns (Wu J. et al., 2021). Long-term intake of these heavy metal ions, even with trace amount in food, will cause some severe diseases, such as cognitive deficits, kidney failure, cardiovascular, and neurological disorders (Zhang et al., 2019). In addition, $\mathrm{Cu}^{2+}$ is an essential element at the trace level in human body. For example, it can play a catalytic action in heme synthesis, but the intake of large quantities can be toxic. It is therefore essential to monitor heavy metals in the food or drinking water. Currently, nanozyme-based analytical method is one of the frontiers in the detection of toxic heavy metal ions. So, to achieve rapid, simple, and sensitive detection of those heavy metal ions, many detection methods coupled with nanozymes have been developed.

For example, Liu et al. prepared an $\mathrm{Au} / \mathrm{Ni}-\mathrm{Fe} \mathrm{LDH} / \mathrm{rGO}$ nanocomposite that both acts as enzyme mimics and surfaceenhanced Raman scattering (SERS) substrate for the removal and detection of organic mercury (MeHg) (Liu et al., 2021). Based on the nanozyme material, $\mathrm{MeHg}$ can be degraded and removed as well as detected with a LOQ of $10 \mathrm{nM}$, which is significant in terms of the multiple applications of nanozymes. Huang et al. reported a new chitosan-functionalized molybdenum(IV) selenide nanosheets (CS- $\mathrm{MoSe}_{2}$ NS) for the colorimetric sensing of $\mathrm{Hg}^{2+}$ (Huang et al., 2019b). With the principle of $\mathrm{Hg}^{2+}$ activated CS-MoSe $\mathrm{NS}_{2}$ nanozyme activities and the indicator of $\mathrm{TMB}, \mathrm{Hg}^{2+}$ ions could be quantitatively and selectively monitored with a LOD of $3.5 \mathrm{nM}$. The method is based on the surface modification of nanozymes, and the catalytic activity can be selectively triggered by specific target, which could be an example for designing other specific nanozymes. Based on $\mathrm{Ag}-\mathrm{CoFe}_{2} \mathrm{O}_{4} /$ reduced graphene oxide ( $\mathrm{rGO}$ ) nanocomposites, Guo et al. established a dual colorimetric and SERS detection assay for the sensitive detection of $\mathrm{Hg}^{2+}$ with a LOD of $0.67 \mathrm{nM}$ (Guo et al., 2018). For the detection of $\mathrm{Pb}^{2+}$ ions, Xie et al. proposed Au@PtNP nanozyme as a colorimetric probe based on the surface leaching of Au@PtNP nanozyme (Xie et al., 2020). By using the $\mathrm{TMB} / \mathrm{H}_{2} \mathrm{O}_{2}$ coloring system, a LOD of $3.0 \mathrm{nM}$ with a linear range from 20 to $800 \mathrm{nM}$ was achieved. Liu et al. presented a facile strategy for selective detection of $\mathrm{Cu}^{2+}$ by combining the peroxidase-like nanozyme activity of gold nanoclusters with amino acid ambidentate nature (Liu et al., 2017). The nanozyme probe showed a linear range of $1-100 \mathrm{nM}$ and a LOD of $0.1 \mathrm{nM}$ using the TMB/ $\mathrm{H}_{2} \mathrm{O}_{2}$ system. Besides, Wen et al. developed a nanozyme-SERS system for detection of fluoride based on reduced $\mathrm{MnCo}_{2} \mathrm{O}_{4} / \mathrm{Au}$ nanotubes, which revealed the key roles of $\bullet \mathrm{OH}$ and $\mathrm{O}_{2}{ }^{--}$radicals in the catalytic mechanism of nanozymes (Wen et al., 2020). The constructed methods are adopting the inhibition principle of heavy metal ions $\left(\mathrm{Cu}^{2+}\right)$ or anion $\left(\mathrm{F}^{-}\right)$toward the catalytic activity of nanozymes.

Various nanozyme-based analytical methods have been developed to analyze food contaminants aiming at achieving good selectivity, high sensitivity, and stability. The nanozyme-based methods may overcome some disadvantages involving high cost of natural enzyme, timeconsuming procedures, and complicated operations. However, it remains a big challenge to obtain controllable and stable nanozymes in the enhanced methods. To compare the performance of nanozyme-based methods in food safety detection, Table 1 listed the detection parameters such as nanozyme classification, analytes, linear range, and limit of detection (LOD), as well as examples of different nanozymes. 
TABLE 1 | Reported nanozyme-based methods in food safety detection.

\begin{tabular}{|c|c|c|c|c|c|c|}
\hline Classification & Nanozyme & Analytes & Analytical method & Linear range & LOD & References \\
\hline \multirow[t]{4}{*}{ Metal-based nanozymes } & Au NP & Patulin & SERS & $0.5 \mathrm{nM} \sim 1 \mu \mathrm{M}$ & $0.085 \mathrm{nM}$ & Zhu et al. (2020b) \\
\hline & Pt NP & Histamine & $\mathrm{BIA}$ & $0.90 \sim 2,699.18 \mu \mathrm{M}$ & $1.15 \mu \mathrm{M}$ & Wang et al. (2020b) \\
\hline & Pd NP & lodine ions & Colorimetry & $0 \sim 6.25 \mathrm{nM}$ & $0.19 \mathrm{nM}$ & He et al. (2020b) \\
\hline & Au@Pt & Aflatoxin $B_{1}$ & NAISA & $0.032 \sim 3,202.36 \mathrm{nM}$ & $0.016 \mathrm{nM}$ & Wu et al. (2020c) \\
\hline \multirow{5}{*}{$\begin{array}{l}\text { Metal oxide-based } \\
\text { nanozymes }\end{array}$} & $\mathrm{Fe}_{3} \mathrm{O}_{4} \mathrm{NP}$ & Phenol & Colorimetry & $1.67 \mu \mathrm{M} \sim 1.2 \mathrm{mM}$ & $3.79 \mu \mathrm{M}$ & Wu et al. (2020a) \\
\hline & $\mathrm{CeO}_{2} @ \mathrm{MnO}_{2} \mathrm{NP}$ & Glucose & PEC sensor & $0.1 \mu \mathrm{M} \sim 0.3 \mathrm{mM}$ & $0.07 \mu \mathrm{M}$ & Wang et al. (2020c) \\
\hline & CuO NP & Ascorbic acid & Fluorometry & $\begin{array}{l}0.75 \sim 7.5 \mu \mathrm{M} / \\
12.5 \sim 125 \mu \mathrm{M}\end{array}$ & $29.2 \mathrm{nM}$ & He et al. (2020c) \\
\hline & $\mathrm{MnO}_{2} \mathrm{NP}$ & Paraoxon & Electrochemistry & $0.36 \sim 72.68 \mu \mathrm{M}$ & $0.09 \mu \mathrm{M}$ & Wu et al. (2021b) \\
\hline & $\mathrm{V}_{2} \mathrm{O}_{5} \mathrm{NP}$ & Dimethylamine & $\begin{array}{l}\text { Chemiresistive } \\
\text { sensor }\end{array}$ & - & $0.11 \mathrm{mM}$ & Mounasamy et al. (2018) \\
\hline \multirow[t]{3}{*}{ Carbon-based nanozymes } & GQDs & Y. enterocolitica & Electrochemistry & $1 \sim 6.23 \times 10^{8} \mathrm{cfu} \mathrm{mL}^{-1}$ & $5 \mathrm{cfu} \mathrm{ml}^{-1}$ & Savas \& Altintas (2019) \\
\hline & $\mathrm{CoO}_{x} \mathrm{H}-\mathrm{GO}$ & Cyanide ions & Colorimetry & $100 \mathrm{nM} 100 \mu \mathrm{M}$ & $32 \mathrm{nM}$ & Lien et al. (2018) \\
\hline & $\begin{array}{l}\text { MoS }_{2} / \\
f \text {-MWCNTs }\end{array}$ & Chloramphenicol & Electrochemistry & $0.08 \sim 1,392 \mu \mathrm{M}$ & $0.015 \mu \mathrm{M}$ & $\begin{array}{l}\text { Govindasamy et al. } \\
\text { (2017) }\end{array}$ \\
\hline \multirow[t]{4}{*}{ Other nanozymes } & LMOF-241 & Aflatoxin $B_{1}$ & Fluorometry & - & $0.15 \mu \mathrm{M}$ & Hu et al. (2015b) \\
\hline & Prussian blue & S. typhimurium & NLISA & $6 \times 10^{3} \sim 10^{6} \mathrm{cfu} \mathrm{mL}^{-1}$ & $6 \times 10^{3} \mathrm{cfu} \mathrm{mL}^{-1}$ & Farka et al. (2018) \\
\hline & $\begin{array}{l}\text { TAPB- } \\
\text { DMTP-COF }\end{array}$ & $\mathrm{Pb}(\mathrm{II})$ ion & Electrochemistry & $0.005 \sim 2.0 \mu \mathrm{M}$ & $1.9 \mathrm{nM}$ & Zhang et al. (2018) \\
\hline & $\mathrm{VS}_{2}$ & Glucose & Colorimetry & $5 \sim 250 \mu \mathrm{M}$ & $1.5 \mu \mathrm{M}$ & Huang et al. (2018b) \\
\hline
\end{tabular}

SERS, surface enhanced Raman scattering; BIA, biomimetic immunoassay method; NAISA, nanozyme and aptamer-based immunosorbent assay; PEC sensor, photoelectrochemical sensor; GQDs, graphene quantum dots; $\mathrm{MoS}_{2} / \mathrm{f}-\mathrm{MWCNTS}$, molybdenum disulfide nanosheets coated on functionalized multiwalled carbon nanotubes; CoO $\mathrm{H}$-GO, cobalt hydroxide/ oxide-modified graphene oxide; OPs, organophosphate pesticides; NLISA, nanozyme-linked immunosorbent assay.

\section{PERSPECTIVES AND CHALLENGES}

Along with their remarkable properties, nanozymes-based analytical techniques have been booming. To drive the development of nanozyme research in food safety, it is essential to open a new avenue that can solve the limitations of the exited analytical methods. Fortunately, most of nanozymes are applied in constructing rapid detection methods like fluorescence, colorimetry, electrochemistry, and biosensors, which has provided some potential opportunities to meet the demands of analytical science. In this view, we summarized the nanozymes-based analytical methods for the rapid and sensitive detection of food contaminants. Though nanozymes can enhance analytical performance, they are new artificial enzymes that are full of challenges remained to be addressed.

1) We explore principles and mechanisms of nanozymes. Although a large number of papers have been reported on nanozymes, few experimental studies focused on the theoretical work and mechanism clarification. It is of great importance to explore the fundamental principles and mechanisms of nanozymes, which can facilitate to reveal the rule of structure-activity relationship and guide the precise design of nanozymes with desirable applications.

2) We develop uniform system and standards. Nanozymes are built up from the concept of enzyme; however, the properties differ a lot from natural enzymes. So, it is difficult to characterize the nanozyme performance in a traditional way. For example, the Michaelis-Menten mechanism is popular in discussing natural enzymes, but it is clear that natural enzymes catalyze a reaction through a homogeneous medium, which is different from nanozymes that occur in a heterogeneous mechanism on the surface of nanomaterials. Thus, uniform system and standards should be constructed to better characterize nanozyme performance.

3) We engineer controllable and functional nanozymes. Since size, morphology, and surface groups pose effects on nanozyme activity and functions, it is favorable to achieve nanozymes with high performance. How to controllably engineer nanozymes and extend their functions by surface modification is an important direction.

4) We evaluate high-performance nanozymes. In developing improved analytical techniques, various nanozymes are 
reported for signal production and amplification. However, when applied to the real applications, the catalytic activity of nanozymes is still relatively low. Compared to natural enzymes, the types of nanozymes are limited, and nanozymes can hardly catalyze one specific substrate. Hence, it is in great need to develop nanozymes with high catalytic activity, various enzymatic activity, and good substrate selectivity.

5) We integrate distinct techniques. It is encouraging that nanozyme-based detection techniques are narrowing the gap to practical-oriented food analytical methods. But it is almost impossible to achieve all the advances in a single detection technique. Thus, it is an alternative to develop nanozymes-based techniques with multimodes for the rapid, accurate, sensitive, and selective detection of food contaminants. For instance, it can greatly improve the specificity and selectivity of nanozymes by coupling with molecular imprinting technique.

In general, nanozymes are in the early stages of the development of the second generation artificial enzymes. The powerful functions of nanozymes make them popular from in vitro detection to in vivo monitoring, and we believe that they will have great potential in the analysis of food contaminants in the near future. The above challenges will be the next frontier for further nanozyme research.

\section{REFERENCES}

Bahreyni, A., Yazdian-Robati, R., Ramezani, M., Abnous, K., and Taghdisi, S. M. (2018). Fluorometric Aptasensing of the Neonicotinoid Insecticide Acetamiprid by Using Multiple Complementary Strands and Gold Nanoparticles. Microchimica Acta 185 (5), 272. doi:10.1007/s00604-018-2805-7

Bajwa, U., and Sandhu, K. S. (2014). Effect of Handling and Processing on Pesticide Residues in Food- a Review. J. Food Sci. Technol. 51, 201-220. doi:10.1007/s13197-011-0499-5

Balgobind, K., Kanchi, S., Sharma, D., Bisetty, K., and Sabela, M. I. (2016). Hybrid of ZnONPs/MWCNTs for Electrochemical Detection of Aspartame in Food and Beverage Samples. J. Electroanalytical Chem. 774, 51-57. doi:10.1016/ j.jelechem.2016.05.021

Bano, K., Khan, W. S., Cao, C., Khan, R. F. H., and Webster, T. J. (2020). "Biosensors for Detection of Marine Toxins," Nanobiosensors: From Design to Application. Editors A. Wu and W. S. Khan (Germany: Wiley-VCH), 329-356. doi:10.1002/9783527345137.ch14

Boruah, P. K., and Das, M. R. (2020). Dual Responsive Magnetic Fe3O4-TiO2/ graphene Nanocomposite as an Artificial Nanozyme for the Colorimetric Detection and Photodegradation of Pesticide in an Aqueous Medium. J. Hazard. Mater. 385, 121516. doi:10.1016/j.jhazmat.2019.121516

Chang, Y.-C., Lin, Y.-S., Xiao, G.-T., Chiu, T.-C., and Hu, C.-C. (2016). A Highly Selective and Sensitive Nanosensor for the Detection of Glyphosate. Talanta 161, 94-98. doi:10.1016/j.talanta.2016.08.029

Cheng, N., Song, Y., Zeinhom, M. M. A., Chang, Y.-C., Sheng, L., Li, H., et al. (2017). Nanozyme-Mediated Dual Immunoassay Integrated with Smartphone for Use in Simultaneous Detection of Pathogens. ACS Appl. Mater. Inter. 9, 40671-40680. doi:10.1021/acsami.7b12734

Ching, K. H., Lin, A., McGarvey, J. A., Stanker, L. H., and Hnasko, R. (2012). Rapid and Selective Detection of Botulinum Neurotoxin Serotype-A and -B with a Single Immunochromatographic Test Strip. J. Immunological Methods 380, 23-29. doi:10.1016/j.jim.2012.03.008

Cimbalo, A., Alonso-Garrido, M., Font, G., and Manyes, L. (2020). Toxicity of Mycotoxins In Vivo on Vertebrate Organisms: A Review. Food Chem. Toxicol. 137, 11116. doi:10.1016/j.fct.2020.111161

\section{AUTHOR CONTRIBUTIONS}

LW and WZ were responsible for conceptualization; LW and SZ were responsible for formal analysis; $\mathrm{LW}, \mathrm{WZ}$, and GL were responsible for funding acquisition; SZ, GW, and YY were responsible for investigation; LW and SZ were responsible for resources and software; LW and WZ were responsible for supervision; LW was responsible for writing the original draft; LW and GL were responsible for writing of review and editing. All authors have read and approved the published version of the manuscript.

\section{FUNDING}

This work was supported by the National Natural Science Foundation of China (31801638, 32060579), the Fund of Key Laboratory of Fermentation Engineering (Ministry of Education) (202105FE09), and the Hainan University Start-Up Scientific Research Projects of China (KYQD(ZR)-21044).

\section{ACKNOWLEDGMENTS}

GL acknowledges the financial support by the University Development Fund (UDF01002012) from the Chinese University of Hong Kong (Shenzhen).

Cui, C., Wang, Q., Liu, Q., Deng, X., Liu, T., Li, D., et al. (2018). Porphyrinbased Porous Organic Framework: An Efficient and Stable PeroxidaseMimicking Nanozyme for Detection of $\mathrm{H} 2 \mathrm{O} 2$ and Evaluation of Antioxidant. Sensors Actuators B: Chem. 277, 86-94. doi:10.1016/ j.snb.2018.08.097

Cui, R., Han, Z., and Zhu, J.-J. (2011). Helical Carbon Nanotubes: Intrinsic Peroxidase Catalytic Activity and its Application for Biocatalysis and Biosensing. Chem. Eur. J. 17, 9377-9384. doi:10.1002/chem.201100478

Devasahayam, G., Scheld, W. M., and Hoffman, P. S. (2010). Newer Antibacterial Drugs for a new century. Expert Opin. Investig. Drugs 19, 215-234. doi:10.1517/ 13543780903505092

Devi, R., Gogoi, S., Barua, S., Sankar Dutta, H., Bordoloi, M., and Khan, R. (2019). Electrochemical Detection of Monosodium Glutamate in Foodstuffs Based on Au@MoS2/chitosan Modified Glassy Carbon Electrode. Food Chem. 276, 350-357. doi:10.1016/j.foodchem.2018.10.024

Dolatabadi, J. E. N., and Kashanian, S. (2010). A Review on DNA Interaction with Synthetic Phenolic Food Additives. Food Res. Int. 43, 1223-1230. doi:10.1016/ j.foodres.2010.03.026

El-Wahab, H. M. F. A., and Moram, G. S. E.-D. (2013). Toxic Effects of Some Synthetic Food Colorants And/or Flavor Additives on Male Rats. Toxicol. Ind. Health 29 (2), 224-232. doi:10.1177/0748233711433935

Fan, K., Wang, H., Xi, J., Liu, Q., Meng, X., Duan, D., et al. (2017). Optimization of Fe3O4 Nanozyme Activity via Single Amino Acid Modification Mimicking an Enzyme Active Site. Chem. Commun. 53, 424-427. doi:10.1039/c6cc08542c

Farka, Z., Čunderlová, V., Horáčková, V., Pastucha, M., Mikušová, Z., Hlaváček, A., et al. (2018). Prussian Blue Nanoparticles as a Catalytic Label in a sandwich Nanozyme-Linked Immunosorbent Assay. Anal. Chem. 90 (3), 2348-2354. doi:10.1021/acs.analchem.7b04883

Fu, J., Zhou, Y., Huang, X., Zhang, W., Wu, Y., Fang, H., et al. (2020). Dramatically Enhanced Immunochromatographic Assay Using Cascade Signal Amplification for Ultrasensitive Detection of Escherichia coli O157:H7 in Milk. J. Agric. Food Chem. 68, 1118-1125. doi:10.1021/acs.jafc.9b07076

Gao, L., Fan, K., and Yan, X. (2020). Iron Oxide Nanozyme: A Multifunctional Enzyme Mimetics for Biomedical Application. Nanozymology 7, 105-140. doi:10.1007/978-981-15-1490-6_5 
Gao, L., Zhuang, J., Nie, L., Zhang, J., Zhang, Y., Gu, N., et al. (2007). Intrinsic Peroxidase-like Activity of Ferromagnetic Nanoparticles. Nat. Nanotech 2, 577-583. doi:10.1038/nnano.2007.260

Garg, B., and Bisht, T. (2016). Carbon Nanodots as Peroxidase Nanozymes for Biosensing. Molecules 21 (12), 1653. doi:10.3390/molecules21121653

Govindasamy, M., Chen, S.-M., Mani, V., Devasenathipathy, R., Umamaheswari, R., Joseph Santhanaraj, K., et al. (2017). Molybdenum Disulfide Nanosheets Coated Multiwalled Carbon Nanotubes Composite for Highly Sensitive Determination of Chloramphenicol in Food Samples Milk, Honey and Powdered Milk. J. Colloid Interf. Sci. 485, 129-136. doi:10.1016/ j.jcis.2016.09.029

Guo, Y., Tao, Y., Ma, X., Jin, J., Wen, S., Ji, W., et al. (2018). A Dual Colorimetric and SERS Detection of $\mathrm{Hg} 2+$ Based on the Stimulus of Intrinsic Oxidase-like Catalytic Activity of Ag-CoFe2O4/reduced Graphene Oxide Nanocomposites. Chem. Eng. J. 350, 120-130. doi:10.1016/j.cej.2018.05.135

Han, J., Zhang, L., Hu, L., Xing, K., Lu, X., Huang, Y., et al. (2018). Nanozymebased Lateral Flow Assay for the Sensitive Detection of Escherichia coli O157:H7 in Milk. J. Dairy Sci. 101, 5770-5779. doi:10.3168/jds.2018-14429

Harms, A., Brodersen, D. E., Mitarai, N., and Gerdes, K. (2018). Toxins, Targets, and Triggers: An Overview of Toxin-Antitoxin Biology. Mol. Cel. 70, 768-784. doi:10.1016/j.molcel.2018.01.003

He, J., Liu, G., Jiang, M., Xu, L., Kong, F., and Xu, Z. (2020a). Development of Novel Biomimetic Enzyme-Linked Immunosorbent Assay Method Based on Au@ $\mathrm{SiO} 2$ Nanozyme Labelling for the Detection of Sulfadiazine. Food Agric. Immunol. 31, 341-351. doi:10.1080/09540105.2020.1728234

He, S.-B., Balasubramanian, P., Hu, A.-L., Zheng, X.-Q., Lin, M.-T., Xiao, M.-X., et al. (2020b). One-pot cascade Catalysis at Neutral pH Driven by CuO Tandem Nanozyme for Ascorbic Acid and Alkaline Phosphatase Detection. Sensors Actuators B: Chem. 321, 128511. doi:10.1016/j.snb.2020.128511

He, S.-B., Chen, F.-Q., Xiu, L.-F., Peng, H.-P., Deng, H.-H., Liu, A.-L., et al. (2020c). Highly Sensitive Colorimetric Sensor for Detection of Iodine Ions Using Carboxylated Chitosan-Coated Palladium Nanozyme. Anal. Bioanal. Chem. 412 (2), 499-506. doi:10.1007/s00216-019-02270-7

Hong, F., Huang, C., Wu, L., Wang, M., Chen, Y., and She, Y. (2021). Highly Sensitive Magnetic Relaxation Sensing Method for Aflatoxin B1 Detection Based on Au NP-Assisted Triple Self-Assembly cascade Signal Amplification. Biosens. Bioelectron. 192, 113489. doi:10.1016/j.bios.2021.113489

Hu, J., Ni, P., Dai, H., Sun, Y., Wang, Y., Jiang, S., et al. (2015a). Aptamer-based Colorimetric Biosensing of Abrin Using Catalytic Gold Nanoparticles. Analyst 140, 3581-3586. doi:10.1039/c5an00107b

Hu, Z., Lustig, W. P., Zhang, J., Zheng, C., Wang, H., Teat, S. J., et al. (2015b). Effective Detection of Mycotoxins by a Highly Luminescent Metal-Organic Framework. J. Am. Chem. Soc. 137 (51), 16209-16215. doi:10.1021/ jacs.5b10308

Huang, L., Chen, K., Zhang, W., Zhu, W., Liu, X., Wang, J., et al. (2018a). ssDNATailorable Oxidase-Mimicking Activity of Spinel $\mathrm{MnCo}_{2} \mathrm{O}_{4}$ for Sensitive Biomolecular Detection in Food Sample. Sensors And Actuators B-Chemical 269, 87-95. doi:10.1016/j.snb.2018.04.150

Huang, L., Sun, D.-W., Pu, H., Wei, Q., Luo, L., and Wang, J. (2019b). A Colorimetric Paper Sensor Based on the Domino Reaction of Acetylcholinesterase and Degradable $\gamma-\mathrm{MnOOH}$ Nanozyme for Sensitive Detection of Organophosphorus Pesticides. Sensors Actuators B: Chem. 290, 573-580. doi:10.1016/j.snb.2019.04.020

Huang, L., Sun, D. W., Pu, H., Wei, Q., and Wei, Q. (2019a). Development of Nanozymes for Food Quality and Safety Detection: Principles and Recent Applications. Compr. Rev. Food Sci. Food Saf. 18, 1496-1513. doi:10.1111/15414337.12485

Huang, L., Zhu, Q., Zhu, J., Luo, L., Pu, S., Zhang, W., et al. (2019c). Portable Colorimetric Detection of Mercury(II) Based on a Non-Noble Metal Nanozyme with Tunable Activity. Inorg. Chem. 58, 1638-1646. doi:10.1021/ acs.inorgchem. $8 \mathrm{~b} 03193$

Huang, L., Zhu, W., Zhang, W., Chen, K., Wang, J., Wang, R., et al. (2018b). Layered Vanadium(IV) Disulfide Nanosheets as a Peroxidase-like Nanozyme for Colorimetric Detection of Glucose. Microchimica Acta 269, 87-95. doi:10.1016/j.snb.2018.04.150

Huang, Y., Ren, J., Ren, J., and Qu, X. (2019d). Nanozymes: Classification, Catalytic Mechanisms, Activity Regulation, and Applications. Chem. Rev. 119 (6), 4357-4412. doi:10.1021/acs.chemrev.8b00672
Jallow, M., Awadh, D., Albaho, M., Devi, V., and Ahmad, N. (2017). Monitoring of Pesticide Residues in Commonly Used Fruits and Vegetables in Kuwait. Ijerph 14 (8), 833. doi:10.3390/ijerph14080833

Jiang, X., Li, D., Xu, X., Ying, Y., Li, Y., Ye, Z., et al. (2008). Immunosensors for Detection of Pesticide Residues. Biosens. Bioelectron. 23, 1577-1587. doi:10.1016/j.bios.2008.01.035

Jiao, L., Xu, W., Yan, H., Wu, Y., Gu, W., Li, H., et al. (2019). A Dopamine-Induced $\mathrm{Au}$ Hydrogel Nanozyme for Enhanced Biomimetic Catalysis. Chem. Commun. 55, 9865-9868. doi:10.1039/c9cc04436a

Khoris, I. M., Takemura, K., Lee, J., Hara, T., Abe, F., Suzuki, T., et al. (2019). Enhanced Colorimetric Detection of Norovirus Using In-Situ Growth of $\mathrm{Ag}$ Shell on Au NPs. Biosens. Bioelectron. 126, 425-432. doi:10.1016/ j.bios.2018.10.067

Kim, M., Kim, M. S., Kweon, S. H., Jeong, S., Kang, M. H., Kim, M. I., et al. (2015). Simple and Sensitive point-of-care Bioassay System Based on Hierarchically Structured Enzyme-Mimetic Nanoparticles. Adv. Healthc. Mater. 4, 1311-1316. doi:10.1002/adhm.201500173

Kuang, Q., Wang, X., Jiang, Z., Xie, Z., and Zheng, L. (2014). High-energy-surface Engineered Metal Oxide Micro- and Nanocrystallites and Their Applications. Acc. Chem. Res. 47, 308-318. doi:10.1021/ar400092x

Kwon, E. Y., Ruan, X., Wang, L., Lin, Y., Du, D., and Van Wie, B. J. (2020). Mesoporous Pd@Pt Nanoparticle-Linked Immunosorbent Assay for Detection of Atrazine. Analytica Chim. Acta 1116, 36-44. doi:10.1016/j.aca.2020.03.045

Li, G., Wu, J., Jin, H., Xia, Y., Liu, J., He, Q., et al. (2020). Titania/Electro-Reduced Graphene Oxide Nanohybrid as an Efficient Electrochemical Sensor for the Determination of Allura Red. Nanomaterials 10 (2), 307. doi:10.3390/ nano 10020307

Li, J., Liu, M., Jiang, J., Liu, B., Tong, H., Xu, Z., et al. (2019). Morphologycontrolled Electrochemical Sensing Properties of CuS Crystals for Tartrazine and sunset Yellow. Sensors Actuators B: Chem. 288, 552-563. doi:10.1016/ j.snb.2019.03.028

Li, R., Liu, X., Qiu, W., and Zhang, M. (2016). In Vivo Monitoring of $\mathrm{H} 2 \mathrm{O} 2$ with Polydopamine and Prussian Blue-Coated Microelectrode. Anal. Chem. 88, 7769-7776. doi:10.1021/acs.analchem.6b01765

Li, S., Liu, X., Chai, H., and Huang, Y. (2018). Recent Advances in the Construction and Analytical Applications of Metal-Organic Frameworks-Based Nanozymes. Trac Trends Anal. Chem. 105, 391-403. doi:10.1016/j.trac.2018.06.001

Liang, M., and Yan, X. (2019). Nanozymes: From New Concepts, Mechanisms, and Standards to Applications. Acc. Chem. Res. 52, 2190-2200. doi:10.1021/ acs.accounts. $9 \mathrm{~b} 00140$

Lien, C.-W., Unnikrishnan, B., Harroun, S. G., Wang, C.-M., Chang, J.-Y., Chang, H.T., et al. (2018). Visual Detection of Cyanide Ions by Membrane-Based Nanozyme Assay. Biosens. Bioelectron. 102, 510-517. doi:10.1016/j.bios.2017.11.063

Liu, B., and Liu, J. (2017). Surface Modification of Nanozymes. Nano Res. 10, 1125-1148. doi:10.1007/s12274-017-1426-5

Liu, H., Guo, Y., Wang, Y., Zhang, H., Ma, X., Wen, S., et al. (2021). A Nanozyme-Based Enhanced System for Total Removal of Organic Mercury and SERS Sensing. J. Hazard. Mater. 405, 124642. doi:10.1016/ j.jhazmat.2020.124642

Liu, P., Wang, Y., Han, L., Cai, Y., Cai, Y., Ren, H., et al. (2020). Colorimetric Assay of Bacterial Pathogens Based on Co3O4 Magnetic Nanozymes Conjugated with Specific Fusion Phage Proteins and Magnetophoretic Chromatography. ACS Appl. Mater. Inter. 12, 9090-9097. doi:10.1021/acsami.9b23101

Liu, T., Tian, J., Cui, L., Liu, Q., Wu, L., and Zhang, X. (2019a). Facile Strategy to Prepare a Metalloporphyrin-Based Hydrophilic Porous Organic Polymer with Enhanced Peroxidase-like Activity and High Stability for Colorimetric Detection of $\mathrm{H} 2 \mathrm{O} 2$ and Glucose. Colloids Surf. B: Biointerfaces 178, 137-145. doi:10.1016/j.colsurfb.2019.03.008

Liu, W., Gan, C., Chang, W., Qileng, A., Lei, H., and Liu, Y. (2019b). Doubleintegrated Mimic Enzymes for the Visual Screening of Microcystin-LR: Copper Hydroxide Nanozyme and G-Quadruplex/hemin DNAzyme. Analytica Chim. Acta 1054, 128-136. doi:10.1016/j.aca.2018.12.018

Liu, Y., Ding, D., Zhen, Y., and Guo, R. (2017). Amino Acid-Mediated 'turn-Off/ turn-On' Nanozyme Activity of Gold Nanoclusters for Sensitive and Selective Detection of Copper Ions and Histidine. Biosens. Bioelectron. 92, 140-146. doi:10.1016/j.bios.2017.01.036

Liu, Y., Wang, J., Song, X., Xu, K., Chen, H., Zhao, C., et al. (2018). Colorimetric Immunoassay for Listeria Monocytogenes by Using Core Gold Nanoparticles, 
Silver Nanoclusters as Oxidase Mimetics, and Aptamer-Conjugated Magnetic Nanoparticles. Microchimica Acta 185 (8), 360. doi:10.1007/s00604-018-2896-1

Lu, T., Zhan, S., Zhou, Y., Chen, X., Huang, X., Leng, Y., et al. (2018). Fluorescence ELISA Based on CAT-Regulated Fluorescence Quenching of CdTe QDs for Sensitive Detection of FB1. Anal. Methods 10, 5797-5802. doi:10.1039/ c8ay02065e

Lustig, W. P., Mukherjee, S., Rudd, N. D., Desai, A. V., Li, J., and Ghosh, S. K. (2017). Metal-organic Frameworks: Functional Luminescent and Photonic Materials for Sensing Applications. Chem. Soc. Rev. 46, 3242-3285. doi:10.1039/c6cs00930a

Ma, X., Li, S., Pang, C., Xiong, Y., and Li, J. (2018). A Cu(II)-anchored Unzipped Covalent Triazine Framework with Peroxidase-Mimicking Properties for Molecular Imprinting-Based Electrochemiluminescent Detection of Sulfaquinoxaline. Microchimica Acta 185 (12), 546. doi:10.1007/s00604-018-3079-9

Manea, F., Houillon, F. B., Pasquato, L., and Scrimin, P. (2004). Nanozymes: GoldNanoparticle-Based Transphosphorylation Catalysts. Angew. Chem. Int. Ed. 43, 6165-6169. doi:10.1002/anie.200460649

Masiá, A., Suarez-Varela, M. M., Llopis-Gonzalez, A., and Picó, Y. (2016). Determination of Pesticides and Veterinary Drug Residues in Food by Liquid Chromatography-Mass Spectrometry: A Review. Analytica Chim. Acta 936, 40-61. doi:10.1016/j.aca.2016.07.023

Mounasamy, V., Mani, G. K., Sukumaran, S., Ponnusamy, D., Tsuchiya, K., Prasad, A. K., and Madanagurusamy, S. (2018). "Vanadium Oxide Nanoparticles for Dimethylamine Vapour Detection," in 2018 International Symposium on Micro-NanoMechatronics and Human Science (MHS), Nagoya, Japan, 9-12 Dec, 2018, (IEEE), 1-5.

Nandhakumar, P., Kim, G., Park, S., Kim, S., Kim, S., Park, J. K., et al. (2020). Metal Nanozyme with Ester Hydrolysis Activity in the Presence of Ammonia-Borane and its Use in a Sensitive Immunosensor. Angew. Chem. Int. Ed. 59 (50), 22419-22422. doi:10.1002/anie.202009737

Nicolini, V., Gambuzzi, E., Malavasi, G., Menabue, L., Menziani, M. C., Lusvardi, G., et al. (2015). Evidence of Catalase Mimetic Activity in Ce3+/Ce4+ Doped Bioactive Glasses. J. Phys. Chem. B 119, 4009-4019. doi:10.1021/jp511737b

Nilam, M., Hennig, A., Nau, W. M., and Assaf, K. I. (2017). Gold Nanoparticle Aggregation Enables Colorimetric Sensing Assays for Enzymatic Decarboxylation. Anal. Methods 9, 2784-2787. doi:10.1039/c7ay00642j

Patel, M. M., Hall, A. J., Vinjé, J., and Parashar, U. D. (2009). Noroviruses: A Comprehensive Review. J. Clin. Virol. 44, 1-8. doi:10.1016/j.jcv.2008.10.009

Pinto, V. E. F., and Patriarca, A. (2017). Alternaria Species and Their Associated Mycotoxins. Methods Mol. Biol. 1542, 13-32. doi:10.1007/978-1-49396707-0_2

Qin, Z., Zhang, J., Liu, Y., Wu, J., Li, G., Liu, J., et al. (2020). A Simple but Efficient Voltammetric Sensor for Simultaneous Detection of Tartrazine and Ponceau 4R Based on TiO2/Electro-Reduced Graphene Oxide Nanocomposite. Chemosensors 8 (3), 70. doi:10.3390/chemosensors 8030070

Rocca, L. M., Gentili, A., PerezFernandez, V., and Tomai, P. (2017). Veterinary Drugs Residues: a Review of the Latest Analytical Research on Sample Preparation and LC-MS Based Methods. Food Additives Contaminants A-Chemistry Anal. Control. Expo. Risk Assess. 34, 766-784.

Savas, S., and Altintas, Z. (2019). Graphene Quantum Dots as Nanozymes for Electrochemical Sensing of Yersinia Enterocolitica in Milk and Human Serum. Materials 12 (13), 2189. doi:10.3390/ma12132189

Shlyapnikov, Y. M., Shlyapnikova, E. A., Simonova, M. A., Shepelyakovskaya, A. O., Brovko, F. A., Komaleva, R. L., et al. (2012). Rapid Simultaneous Ultrasensitive Immunodetection of Five Bacterial Toxins. Anal. Chem. 84, 5596-5603. doi:10.1021/ac300567f

Song, Y., Qiao, J., Liu, W., and Qi, L. (2020). Norfloxacin Detection Based on the Peroxidase-like Activity Enhancement of Gold Nanoclusters. Anal. Bioanal. Chem. 413 (4), 979-985. doi:10.1007/s00216-020-03056-y

Stolker, A. A. M., and Brinkman, U. A. T. (2005). Analytical Strategies for Residue Analysis of Veterinary Drugs and Growth-Promoting Agents in FoodProducing Animals-A Review. J. Chromatogr. A 1067, 15-53. doi:10.1016/ j.chroma.2005.02.037

Su, Y., Wu, D., Chen, J., Chen, G., Hu, N., Wang, H., et al. (2019). Ratiometric Surface Enhanced Raman Scattering Immunosorbent Assay of Allergenic Proteins via Covalent Organic Framework Composite Material Based Nanozyme Tag Triggered Raman Signal "Turn-On" and Amplification. Anal. Chem. 91, 11687-11695. doi:10.1021/acs.analchem.9b02233
Sun, H., Zhou, Y., Ren, J., and Qu, X. (2018). Carbon Nanozymes: Enzymatic Properties, Catalytic Mechanism, and Applications. Angew. Chem. Int. Ed. 57 (30), 9224-9237. doi:10.1002/anie.201712469

Tang, D., Tang, J., Su, B., and Chen, G. (2011). Gold Nanoparticles-Decorated Amine-Terminated Poly(amidoamine) Dendrimer for Sensitive Electrochemical Immunoassay of Brevetoxins in Food Samples. Biosens. Bioelectron. 26, 2090-2096. doi:10.1016/j.bios.2010.09.012

Tang, T., Cao, S., Xi, C., Li, X., Zhang, L., Wang, G., et al. (2020). Chitosan Functionalized Magnetic Graphene Oxide Nanocomposite for the Sensitive and Effective Determination of Alkaloids in Hotpot. Int. J. Biol. Macromolecules 146, 343-352. doi:10.1016/j.ijbiomac.2019.12.259

Tao, X., Wang, X., Liu, B., and Liu, J. (2020). Conjugation of Antibodies and Aptamers on Nanozymes for Developing Biosensors. Biosens. Bioelectron. 168, 112537. doi:10.1016/j.bios.2020.112537

Tian, L., Zhang, Y., Wang, L., Geng, Q., Liu, D., Duan, L., et al. (2020). Ratiometric Dual Signal-Enhancing-Based Electrochemical Biosensor for Ultrasensitive Kanamycin Detection. ACS Appl. Mater. Inter. 12, 52713-52720. doi:10.1021/acsami.0c15898

Velmurugan, M., Karikalan, N., Chen, S.-M., and Karuppiah, C. (2016). Core-shell like $\mathrm{Cu} 2 \mathrm{O}$ Nanocubes Enfolded with $\mathrm{Co}(\mathrm{OH}) 2$ on Reduced Graphene Oxide for the Amperometric Detection of Caffeine. Microchim Acta 183, 2713-2721. doi:10.1007/s00604-016-1914-4

Vernekar, A. A., Das, T., Ghosh, S., and Mugesh, G. (2016). A Remarkably Efficient MnFe2O4-Based Oxidase Nanozyme. Chem. Asian J. 11, 72-76. doi:10.1002/ asia.201500942

Wang, H., Wan, K., and Shi, X. (2019). Recent Advances in Nanozyme Research. Adv. Mater. 31 (45), 1805368. doi:10.1002/adma.201805368

Wang, H., Yang, W., Wang, X., Huang, L., Zhang, Y., and Yao, S. (2020a). A $\mathrm{CeO} 2 @ \mathrm{MnO} 2$ Core-Shell Hollow Heterojunction as Glucose Oxidase-like Photoenzyme for Photoelectrochemical Sensing of Glucose. Sensors Actuators B: Chem. 304, 127389. doi:10.1016/j.snb.2019.127389

Wang, X.-F., Zhou, Y., Xu, J.-J., and Chen, H.-Y. (2009). Signal-on Electrochemiluminescence Biosensors Based on CdS-Carbon Nanotube Nanocomposite for the Sensitive Detection of Choline and Acetylcholine. Adv. Funct. Mater. 19, 1444-1450. doi:10.1002/adfm.200801313

Wang, X., Song, X., Si, L., Xu, L., and Xu, Z. (2020b). A Novel Biomimetic Immunoassay Method Based on Pt Nanozyme and Molecularly Imprinted Polymer for the Detection of Histamine in Foods. Food Agric. Immunol. 31 (1), 1036-1050. doi:10.1080/09540105.2020.1807916

Wang, Z., Yao, X., Zhang, Y., Wang, R., Ji, Y., Sun, J., et al. (2020c). Functional Nanozyme Mediated Multi-Readout and Label-free Lateral Flow Immunoassay for Rapid Detection of Escherichia coli O157:H7. Food Chem. 329, 127224. doi:10.1016/j.foodchem.2020.127224

Weerathunge, P., Ramanathan, R., Shukla, R., Sharma, T. K., and Bansal, V. (2014). Aptamer-controlled Reversible Inhibition of Gold Nanozyme Activity for Pesticide Sensing. Anal. Chem. 86, 11937-11941. doi:10.1021/ac5028726

Wei, J., Yang, L., Luo, M., Wang, Y., and Li, P. (2019). Nanozyme-assisted Technique for Dual Mode Detection of Organophosphorus Pesticide. Ecotoxicology Environ. Saf. 179, 17-23. doi:10.1016/j.ecoenv.2019.04.041

Wen, S., Zhang, Z., Zhang, Y., Liu, H., Ma, X., Li, L., et al. (2020). Ultrasensitive Stimulation Effect of Fluoride Ions on a Novel Nanozyme-SERS System. ACS Sustain. Chem. Eng. 8 (32), 11906-11913. doi:10.1021/acssuschemeng.0c02935

Winckler, C., and Grafe, A. (2001). Use of Veterinary Drugs in Intensive Animal Production. J. Soils Sediments 1, 66-70. doi:10.1007/bf02987711

Wu, J., Wang, X., Wang, Q., Lou, Z., Li, S., Zhu, Y., et al. (2019a). Nanomaterials with Enzyme-like Characteristics (Nanozymes): Next-Generation Artificial Enzymes (II). Chem. Soc. Rev. 48 (4), 1004-1076. doi:10.1039/c8cs00457a

Wu, J., Yang, Q., Li, Q., Li, H., and Li, F. (2021a). Two-Dimensional MnO2 Nanozyme-Mediated Homogeneous Electrochemical Detection of Organophosphate Pesticides without the Interference of $\mathrm{H} 2 \mathrm{O} 2$ and Color. Anal. Chem. 93 (8), 4084-4091. doi:10.1021/acs.analchem.0c05257

Wu, L., Ding, F., Yin, W., Ma, J., Wang, B., Nie, A., et al. (2017). From Electrochemistry to Electroluminescence: Development and Application in a Ratiometric Aptasensor for Aflatoxin B1. Anal. Chem. 89, 7578-7585. doi:10.1021/acs.analchem.7b01399

Wu, L., Li, G., Xu, X., Zhu, L., Huang, R., and Chen, X. (2019b). Application of Nano-ELISA in Food Analysis: Recent Advances and Challenges. Trac Trends Anal. Chem. 113, 140-156. doi:10.1016/j.trac.2019.02.002 
Wu, L., Yan, H., Wang, J., Liu, G., and Xie, W. (2019c). Tyrosinase Incorporated with Au-Pt@SiO2 Nanospheres for Electrochemical Detection of Bisphenol A. J. Electrochem. Soc. 166 (8), B562-B568. doi:10.1149/2.0141908jes

Wu, L., Yin, W., Tang, K., Li, D., Shao, K., Zuo, Y., et al. (2016). Enzymatic Biosensor of Horseradish Peroxidase Immobilized on Au-Pt nanotube/AuGraphene for the Simultaneous Determination of Antioxidants. Analytica Chim. Acta 933, 89-96. doi:10.1016/j.aca.2016.06.020

Wu, L., Zhou, M., Liu, C., Chen, X., and Chen, Y. (2021b). Double-enzymesmediated $\mathrm{Fe}^{2+} / \mathrm{Fe}^{3+}$ Conversion as Magnetic Relaxation Switch for Pesticide Residues Sensing. J. Hazard. Mater. 403, 123619.

Wu, L., Zhou, M., Wang, Y., and Liu, J. (2020a). Nanozyme and Aptamer- Based Immunosorbent Assay for Aflatoxin B1. J. Hazard. Mater. 399, 123154. doi:10.1016/j.jhazmat.2020.123154

Wu, L., Zhu, L., Ma, J., Li, J., Liu, J., and Chen, Y. (2020b). DNA Enzyme Mediated Ratiometric Fluorescence Assay for $\mathrm{Pb}$ (II) Ion Using Magnetic NanosphereLoaded Gold Nanoparticles and CdSe/ZnS Quantum Dots. Microchimica Acta 187, 1-9. doi:10.1007/s00604-020-04230-w

Wu, S., Guo, D., Xu, X., Pan, J., and Niu, X. (2020c). Colorimetric Quantification and Discrimination of Phenolic Pollutants Based on Peroxidase-like Fe3O4 Nanoparticles. Sensors Actuators B: Chem. 303, 127225. doi:10.1016/ j.snb.2019.127225

Wu, Y., Chen, Q., Liu, S., Xiao, H., Zhang, M., and Zhang, X. (2019d). Surface Molecular Imprinting on G-C3n4 Photooxidative Nanozyme for Improved Colorimetric Biosensing. Chin. Chem. Lett. 30, 2186-2190. doi:10.1016/ j.cclet.2019.08.014

Xi, J., Wei, G., An, L., Xu, Z., Xu, Z., Fan, L., et al. (2020). Copper/Carbon Hybrid Nanozyme: Tuning Catalytic Activity by the Copper State for Antibacterial Therapy. Nano Lett. 19 (11), 7645-7654. doi:10.1021/ acs.nanolett.9b02242

Xie, Z., Shi, M., Wang, L. Y., Peng, C. F., and Wei, X. L. (2020). Colorimetric Determination of $\mathrm{Pb}^{2+}$ Ions Based on Surface Leaching of Au@Pt Nanoparticles as Peroxidase Mimic. Microchimica Acta 187, 1-7. doi:10.1007/s00604-02004234-6

Xu, Z., Long, L.-l., Chen, Y.-q., Chen, M.-L., and Cheng, Y.-H. (2021). A Nanozyme-Linked Immunosorbent Assay Based on Metal-Organic Frameworks (MOFs) for Sensitive Detection of Aflatoxin B1. Food Chem. 338, 128039. doi:10.1016/j.foodchem.2020.128039

Yan, M., Chen, G., She, Y., Ma, J., Hong, S., and Shao, Y. (2019). Sensitive and Simple Competitive Biomimetic Nanozyme-Linked Immunosorbent Assay for Colorimetric and Surface-Enhanced Raman Scattering Sensing of Triazophos. J. Agri. Food Chem. 67, 9658-9666.

Yang, F., Jiang, X., Zhong, X., Wei, S., and Yuan, R. (2018a). Highly Sensitive Electrochemiluminescence Detection of Mucin1 Based on V2O5 Nanospheres as Peroxidase Mimetics to Catalyze $\mathrm{H} 2 \mathrm{O} 2$ for Signal Amplification. Sensors Actuators B: Chem. 265, 126-133. doi:10.1016/j.snb.2018.03.031

Yang, Q., Wang, J., Chen, X., Yang, W., Pei, H., Hu, N., et al. (2018b). The Simultaneous Detection and Removal of Organophosphorus Pesticides by a Novel Zr-MOF Based Smart Adsorbent. J. Mater. Chem. A. 6, 2184-2192. doi:10.1039/c7ta08399h

Yang, W., Zhang, G., Ni, J., Wang, Q., and Lin, Z. (2021). From Signal Amplification to Restrained Background: Magnetic Graphene Oxide Assisted Homogeneous Electrochemiluminescence Aptasensor for Highly Sensitive Detection of Okadaic Acid. Sensors And Actuators B-Chemical 327, 128872. doi:10.1016/j.snb.2020.128872
Yue, X., Luo, X., Zhou, Z., and Bai, Y. (2019). Selective Electrochemical Determination of Tertiary Butylhydroquinone in Edible Oils Based on an In-Situ Assembly Molecularly Imprinted Polymer Sensor. Food Chem. 289, 84-94. doi:10.1016/j.foodchem.2019.03.044

Zain, M. E. (2011). Impact of Mycotoxins on Humans and Animals. J. Saudi Chem. Soc. 15, 129-144. doi:10.1016/j.jscs.2010.06.006

Zhang, L., Liu, Z., Deng, Q., Sang, Y., Dong, K., Ren, J., et al. (2021). NatureInspired Construction of MOF@COF Nanozyme with Active Sites in Tailored Microenvironment and Pseudopodia-Like Surface for Enhanced Bacterial Inhibition. Angew. Chem. Int. Ed. 60 (7), 3469-3474. doi:10.1002/ anie. 202012487

Zhang, T., Gao, C., Huang, W., Chen, Y., Wang, Y., and Wang, J. (2018). Covalent Organic Framework as a Novel Electrochemical Platform for Highly Sensitive and Stable Detection of lead. Talanta 188, 578-583. doi:10.1016/ j.talanta.2018.06.032

Zhang, X., Wu, D., Zhou, X., Yu, Y., Liu, J., Hu, N., et al. (2019). Recent Progress in the Construction of Nanozyme-Based Biosensors and Their Applications to Food Safety Assay. Trac Trends Anal. Chem. 121, 115668. doi:10.1016/ j.trac.2019.115668

Zhang, Z., Tian, Y., Huang, P., and Wu, F. Y. (2020). Using Target-specific Aptamers to Enhance the Peroxidase-like Activity of Gold Nanoclusters for Colorimetric Detection of Tetracycline Antibiotics. Talanta 208, 120342. doi:10.1016/j.talanta.2019.120342

Zhou, Y., Wei, Y., Ren, J., and Qu, X. (2020). A Chiral Covalent Organic Framework (COF) Nanozyme with Ultrahigh Enzymatic Activity. Mater. Horiz. 7, 3291-3297. doi:10.1039/d0mh01535k

Zhu, X., Mao, X., Wang, Z., Feng, C., Chen, G., and Li, G. (2017). Fabrication of Nanozyme@DNA Hydrogel and its Application in Biomedical Analysis. Nano Res. 10, 959-970. doi:10.1007/s12274-016-1354-9

Zhu, Y., Wu, J., Han, L., Wang, X., Li, W., Guo, H., et al. (2020b). Nanozyme Sensor Arrays Based on Heteroatom-Doped Graphene for Detecting Pesticides. Anal. Chem. 92, 7444-7452. doi:10.1021/acs.analchem.9b05110

Zhu, Y., Wu, L., Yan, H., Lu, Z., Yin, W., and Han, H. (2020a). Enzyme Induced Molecularly Imprinted Polymer on SERS Substrate for Ultrasensitive Detection of Patulin. Analytica Chim. Acta 1101, 111-119. doi:10.1016/ j.aca.2019.12.030

Conflict of Interest: The authors declare that the research was conducted in the absence of any commercial or financial relationships that could be construed as a potential conflict of interest.

Publisher's Note: All claims expressed in this article are solely those of the authors and do not necessarily represent those of their affiliated organizations, or those of the publisher, the editors, and the reviewers. Any product that may be evaluated in this article, or claim that may be made by its manufacturer, is not guaranteed or endorsed by the publisher.

Copyright $\odot 2021 \mathrm{Wu}$, Zhou, Wang, Yun, Liu and Zhang. This is an open-access article distributed under the terms of the Creative Commons Attribution License (CC $B Y)$. The use, distribution or reproduction in other forums is permitted, provided the original author(s) and the copyright owner(s) are credited and that the original publication in this journal is cited, in accordance with accepted academic practice. No use, distribution or reproduction is permitted which does not comply with these terms. 